Können natürliche, biologische Abbau- oder Umwandlungsprozesse Schadstoffe, die sich durch menschliche Tätigkeiten in der Umwelt verbreitet haben, unschädlich machen? Diese Frage wird immer wieder hoffnungsvoll gestellt, besonders wenn Laborversuche bestätigen, daß Umweltgifte wie zum Beispiel polychlorierte Biphenyle (PCBs) im Prinzip durch Mikroorganismen abgebaut oder zumindest in ihrer chemischen Struktur verändert werden können. Die Tatsache, daß PCBs in der Umwelt trotzdem persistent und weitverbreitet sind, löst dann vielerorts Mißtrauen und Ungläubigkeit aus. Prinzipielle Abbaubarkeit oder Umwandlungen, gezeigt in Laborversuchen, genügen eben nicht, um das Umweltverhalten von Chemikalien abschließend zu beurteilen. Neben ihrem Transportverhalten, das vor allem durch physikalisch-chemische Eigenschaften bestimmt wird, spielen biologische Faktoren eine wichtige Rolle. Im Falle der PCBs wirken grundsätzlich verschiedene bakterielle Reaktionsmechanismen, je nachdem, ob sich die Verbindungen in einem sauerstoffhaltigen oder -freien Milieu befinden. Daher müssen sowohl aerobe als auch anaerobe Umwandlungsprozesse berücksichtigt werden, um das Schicksal der PCBs in der Umwelt zu verstehen. Dazu gehört auch die Betrachtung der Prozesse auf der molekularen Ebene - Stoffaufnahme, enzymatische Reaktionsmechanismen, Regulation der Enzymsynthesen und Genetik. Die Entwicklung neuer Strategien zur Entsorgung von Restbeständen an PCBs oder zur Reinigung von PCB-kontaminierten Umweltkompartimenten ist ebenso angewiesen auf Erkenntnisse der Mikrobiologie wie auf solche aus Chemie, Physik, Toxikologie, Ingenieurwesen und anderen Disziplinen.

\section{Mikrobielle Umwandlungen polychlorierter Biphenyle (PCBs)}

Hans-Peter E. Kohler*, Doris Kohler-Staub und Alfredo C. Alder chlorine content of the molecules is generally not reduced.

In contrast, under anaerobic conditions $P C B s$ are reductively dechlorinated at the meta- and para-positions with accumulation of ortho-substituted chlorobiphenyls.

Recent advances in research concerning biotransformation of PCBs and genetics of $P C B$-transforming organisms has lead to the opinion that the potential of microorganisms for decontaminating PCB-containing sites should be further investigated and appropriate techniques, especially combinations of anaerobic and aerobic processes, should be developed. Future research will have to show, whether microbially mediated processes can help to deal with the global environmental PCB contamination.

* Postadresse : Dr. H.-P. E. Kohler Abteilung Mikrobiologie Eidgenössische Anstalt für Wasserversorgung, Abwasserreinigung und Gewässerschutz (EAWAG)

CH-8600 Dübendorf (Schweiz)

Keywords: aerobic, anaerobic, biodegradation, bioremediation, dioxygenases, microbial transformations, microorganisms, PCB contamination, polychlorinated

\section{Einleitung ${ }^{1)}$}

PCBs sind problematische Umweltgifte anthropogenen Ursprungs, die sich in der Biosphäre nur sehr langsam verändern und deshalb als extrem persistente Schadstoffe gelten. Durch ihr hohes Bioakkumulationspotential und ihre Toxizität haben diese Chemikalien schlechterdings auf alle Lebewesen negative Auswirkungen ${ }^{[1]}$. Aufgrund ihrer für technische Anwendungen begehrten physikalischen und chemischen Eigenschaften wurden PCBs seit 1929 industriell hergestellt und verwendet. Ende der siebziger Jahre, nach Erkennen des umwelt- und gesundheitsschädigenden Charakters der PCBs, wurden ihre Produktion und ihr Gebrauch in den westlichen Industrieländern verboten (zum Beispiel USA) oder stark eingeschränkt (zum Beispiel Bundesrepublik Deutschland). In der Schweiz ist das Herstellen, Abgeben, Einführen und Verwenden von PCBs oder PCB-haltigen Geräten seit 1986 gemäß Eidgenössischer Verordnung für umweltgefährdende Stoffe (sogenannte Stoffverordnung) verboten. In Betrieb stehende Geräte müssen bis 1998 außer Betrieb genommen und der Entsorgung zugeführt werden ${ }^{[2]}$.

In den letzten 50 Jahren wurden weltweit über eine Million Tonnen PCBs produziert. Ein großer Teil davon gelangte auf mannigfaltigen Wegen in die Umwelt, wo sich die außerordentliche Widerstandsfähigkeit der PCBs gegenüber physikalischen, chemischen und biologischen Abbauvorgängen als großer Nachteil erwies: Jeder Bereich des globalen Ökosystems ist heute mit PCBs kontaminiert ${ }^{[3]}$. Es wird angenommen, daß sich ein Drittel der insgesamt produzierten Menge unverändert in mobilen Umweltreservoirs befindet.

Mangels Rückholbarkeit von PCBs aus der Umwelt führen Produktionsverbot oder Eintragsverminderung leider noch nicht zur endgültigen Lösung des PCBProblems. Aus den zur Zeit verfügbaren Daten kann man schließen, daß der natürliche Abbau von $\mathrm{PCB}$ sur innerhalb geologischer Zeiträume ein Ausmaß erreicht, welches zum Verschwinden oder zu einer signifikanten Herabsetzung der Umweltbelastung genügen würde ${ }^{[1]}$. Es wird deshalb vor der Hoffnung gewarnt, die PCB-Problematik löse sich biphenyls, reductive dechlorination
1) Vergleiche dazu auch den Kommentar von W. Giger: "Polychlorierte Biphenyle: 25 Jahre 'klassische' Umweltchemikalien", GAIA 1 (1992) 50-53. 
in absehbarer Zeit dank natürlicher Abbauprozesse von selbst.

Die Vermutung, daß allenfalls doch stattfindende biologische Abbauvorgänge in erster Linie Stoffwechsel-Aktivitäten von Mikroorganismen zuzuschreiben sind ${ }^{[4]}$, führte in den Gebieten der Umweltmikrobiologie und -toxikologie zu konkreten, neuartigen Fragestellungen und Forschungszielen. Einerseits ist es von Interesse, Transformationsraten und -produkte von PCBs in verschiedenen natürlichen Umgebungen zu kennen, um so die ökotoxikologischen Auswirkungen der PCBs und ihrer Metaboliten besser abschätzen und verstehen zu können. Anderseits wird ein tieferes Verständnis der metabolischen und genetischen Eigenschaften von einzelnen Mikroorganismen angestrebt mit dem langfristigen Ziel, Methoden zur biologischen Säuberung von PCB-kontaminierten Standorten zu entwickeln.

\section{Was sind PCBs?}

Die chemische Grundstruktur der PCBs bildet das Biphenylmolekül (Figur 1). In jedem der beiden miteinander verknüpften sechsgliedrigen Ringe kann an fünf unterschiedlichen Kohlenstoffatomen ein Chloratom gebunden sein. Daraus ergeben sich zehn Klassen von Verbindungen, welche sich durch die Anzahl der Chloratome unterscheiden und als Homologe bezeichnet werden. Für jedes Homologe existieren zwischen 1 und 46 Isomere: während es für Decachlorbiphenyl $\left(\mathrm{C}_{12} \mathrm{Cl}_{10}\right)$ nur ein Isomer gibt, existieren 46 Isomere mit der Summenformel $\mathrm{C}_{12} \mathrm{H}_{5} \mathrm{Cl}_{5}$ (Pentachlorbiphenyle). Insgesamt ergibt das 209 verschiedene Verbindungen, die sich in Anzahl und Position der Chloratome unterscheiden und die als Kongenere bezeichnet werden (Tabelle 1).

Die chemische Synthese von PCBs beruht auf direkter Chlorierung des Kohlenwasserstoffs Biphenyl in Anwesenheit eines Katalysators wie Eisenchlorid oder Eisenspäne. Zur Reinigung wird das Rohprodukt mit Alkali behandelt und destilliert. Das Endprodukt besteht aus einer komplexen Mischung zahlreicher PCB-Kongenere. PCBGemische enthalten häufig auch noch polychlorierte Dibenzofurane (PCDFs), welche als Spuren (im $\mu \mathrm{g} / \mathrm{g}$-Bereich) nachgewiesen werden konnten ${ }^{[5]}$, und deren Anteil in Abhängigkeit von den Produktionsbedingungen variiert.

In den USA wurden PCBs von Monsanto unter dem Namen Aroclor ${ }^{\otimes}$, in

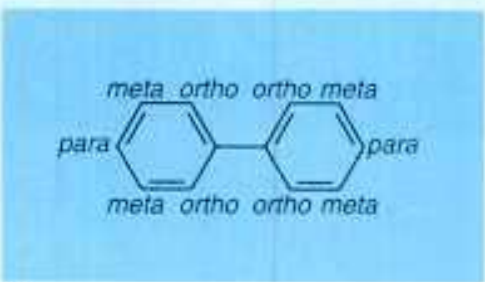

(1)

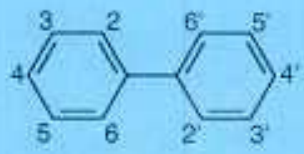

(2)

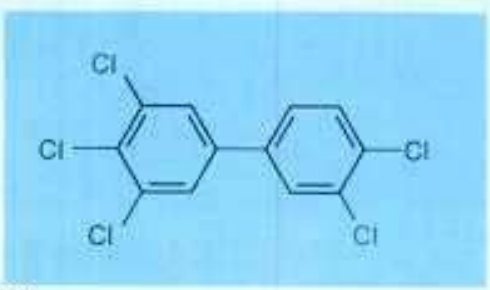

(3)

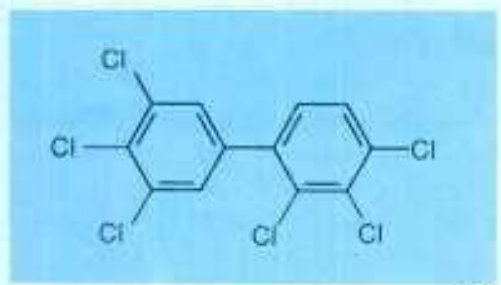

(4)

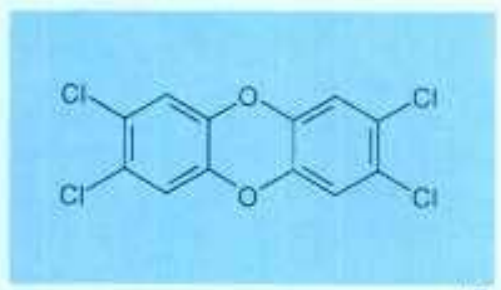

(5)

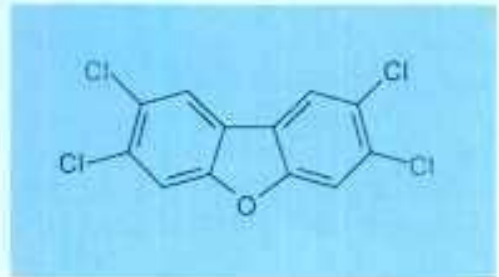

(6)
Figur 1. Strukturformeln: Die Stellung der Kohlenstoffatome im Biphenyl-Doppelring wird mit Präfixen (1) oder Ziffern (2) angegeben. 3,3',4,4',5,-Pentachlorbiphenyl (3) ist eines der drei toxischsten Kongenere. Da es keine ortho-Substituenten hat, kann es eine koplanare Konformation einnehmen, und seine räumliche Molekülstruktur wird somit ähnlich derjenigen von 2,3,7,8-Tetrachlordibenzodioxin (5), das als der potenteste synthetische Schadstoff überhaupt gilt. Durch Einbau eines ortho-Chlorsubstituenten (4) wird die Toxizität herabgesetzt. Das geht einher mit der Tatsache, daß die koplanare Konformation in diesem Falle energetisch ungünstiger wird. 2,3,7,8-Tetrachlordibenzofuran (6) ist ein Vertreter einer Substanzklasse, die als Verunreinigung in kommerziellen PCB-Gemischen auftreten kann und ähnliche toxische Syndrome bewirkt wie die polychlorierten Dibenzodioxine.
Deutschland von Bayer unter dem Namen Clophen ${ }^{\oplus}$ und in Japan von Kanegafuchi unter dem Namen Kanechlor ${ }^{\mathbb{B}}$ hergestellt und vertrieben. Die AroclorProdukte wurden mit einer vierstelligen Zahl 12XX gekennzeichnet. Die ersten beiden Ziffern symbolisieren die Molekülgrundstruktur: 12 steht für die zwölf
Kohlenstoffatome des Biphenylgerüsts. Die letzten beiden Ziffern geben den Chloranteil in Gewichtsprozenten an. Präparate mit einem niedrigen Chlorgehalt (bis 54\%) sind viskose Flüssigkeiten, während diejenigen mit höherem Chlorgehalt (wie Aroclor 1260) unter Normalbedingungen als Feststoffe vorliegen.
Tabelle 1. Zusammensetzung von homologen polychlorierten Biphenylen

\begin{tabular}{|c|c|c|c|c|}
\hline Summentormel & $\begin{array}{l}\text { Molekular- } \\
\text { gawicht a) }\end{array}$ & $\begin{array}{l}\text { Durchschnittliches } \\
\text { Molekulargewicht b) }\end{array}$ & $\begin{array}{l}\text { Prozent } \\
\text { Chlor }\end{array}$ & $\begin{array}{l}\text { Anzahl } \\
\text { Isomere }\end{array}$ \\
\hline 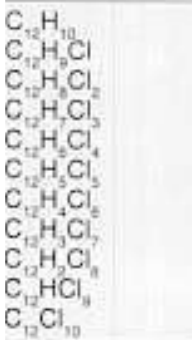 & $\begin{array}{l}154.1 \\
188.0 \\
222.0 \\
256.0 \\
289.0 \\
323.9 \\
357.8 \\
391.8 \\
425.8 \\
459.7 \\
493.7\end{array}$ & $\begin{array}{l}154.2 \\
188.7 \\
223.1 \\
257.6 \\
292.0 \\
326.4 \\
360.9 \\
395.3 \\
429.8 \\
464.2 \\
498.7\end{array}$ & $\begin{array}{r}0 \\
19 \\
32 \\
41 \\
49 \\
54 \\
59 \\
63 \\
66 \\
69 \\
71\end{array}$ & $\begin{array}{r}1 \\
3 \\
12 \\
24 \\
42 \\
46 \\
42 \\
24 \\
12 \\
3 \\
1\end{array}$ \\
\hline
\end{tabular}

a) Bezogen aut ${ }^{15} \mathrm{Cl}$ (relatives Atomgewicht 34.969), ${ }^{12} \mathrm{C}$ (Atorngewicht 12.000) und ${ }^{1} \mathrm{H}$ (Atomgewicht 1.0079): bezieht sich auf die kleinste Masse im 'Fingerabdruck' des Massenspektrums. a) "Durchschnittliches" Molekulargewicht, basierond auf der natürlichen Häufigkoit von Chlor (Atomgewicht 35.453), Kohlenstoff (Atomgewicht 12.011) und Wasserstoff (Atomgewicht 1.0088). 


\section{Eigenschaften und Verwendung der PCBs}

PCBs sind beständig gegen Basen, Säuren, Oxidation und Hitze; sie sind gut verträglich mit anderen organischen Verbindungen (also können sie Ölen beigemischt werden); und sie sind als elektrische Nichtleiter nicht brennbar, nicht entflammbar, nicht korrosiv, wenig flüchtig und wenig akut toxisch. Diese in vieler Hinsicht vorteilhaften chemischen und physikalischen Eigenschaften der PCBs, die schon vor Beginn dieses Jahrhunderts bekannt waren, gaben ab 1929 den Anstoß zur industriellen Produktion.

PCBs galten als ideale Werkstoffe für vielfältige technische Anwendungen. Sie wurden als Kühlmittel in Transformatoren, als Dielektrikum in Kondensatoren, als Hydraulikflüssigkeit in Hubwerkzeugen (vor allem im Bergbau) sowie als Werkstoff in anderen geschlossenen Systemen benutzt. Bald wurden PCBs auch in offenen Systemen, als Zusatz zu Schmiermitteln, Kunststoffen, Wachsen, Farben, Lacken und Klebstoffen, in wachsenden Mengen verwendet.

\section{PCBs in der Umwelt}

Die sich rasch ausbreitende Verwendung von PCBs und ihre leichtfertige Beseitigung haben dazu geführt, daß bis heute ungefähr ein Drittel der gesamten Weltproduktion in die Umwelt gelangen konnte. Zudem muß aus mehreren Quellen (zum Beispiel Kleinkondensatoren, siehe Legende zu Figur 2) mit fortlaufenden, bis über das Jahr 2000 hinaus andauernden Einträgen von PCBs in die Umwelt gerechnet werden ${ }^{[6]}$.

PCBs können heute als allgegenwärtige Umweltgifte bezeichnet werden (vergleiche dazu den Exkurs auf Seite $160)$. Sie sind praktisch in allen Meerespflanzen und -tieren, in Süßwasserfischen, Vögeln, Vogeleiern, Säugetieren und auch im Menschen nachweisbar. Trotz proklamiertem Produktions- und Verwendungsstillstand nehmen die Gehalte an PCBs im menschlichen Fettgewebe und in der Milch stillender Frauen, im Gegensatz zum Gehalt an DDT (1,1,1-Trichlor-2,2-bis(para-chlorphenyl)ethan), beispielsweise in Deutschland nicht signifikant $a b^{[7]}$.

PCBs werden leicht aus lokalen oder regionalen Kontaminationsstellen verfrachtet und in praktisch sämtlichen

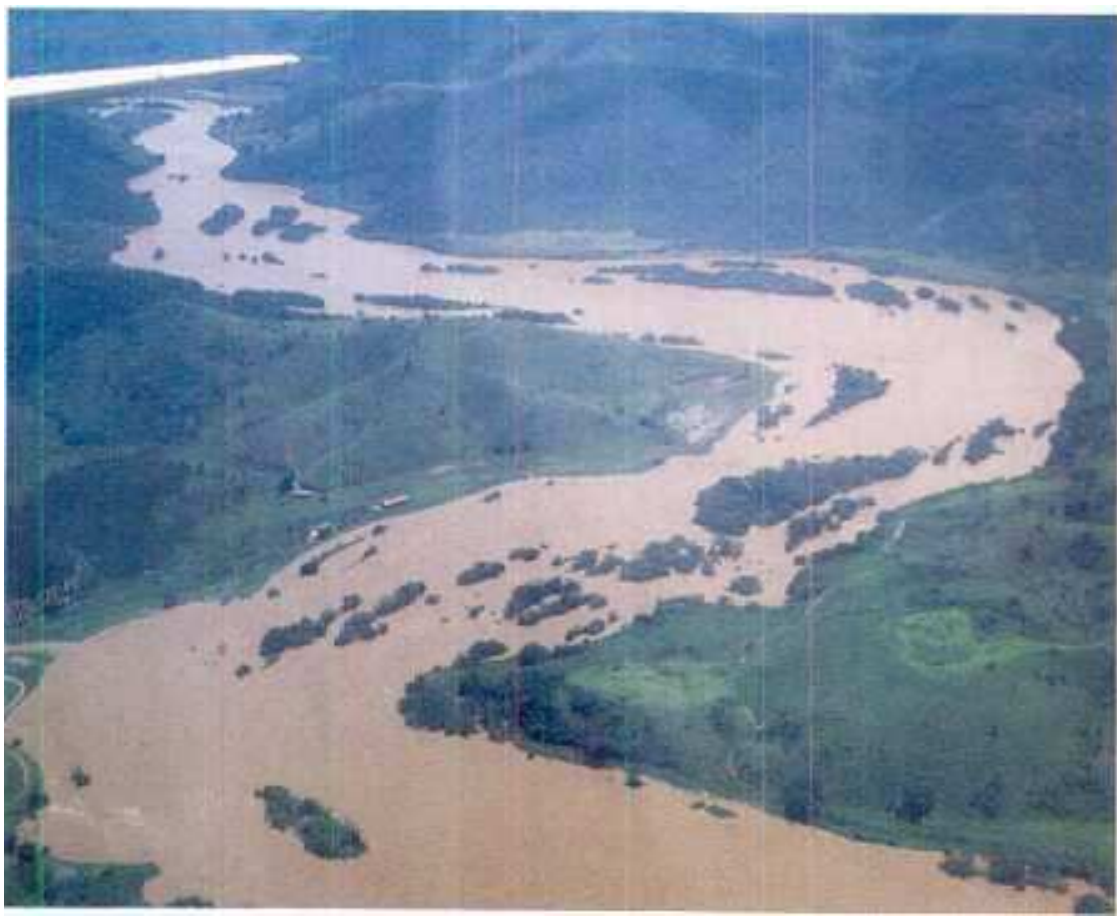

Figur 2. Flußlandschaft des Rio Paraiba do Sul. In einem industriellen Betrieb im Staate Rio de Janeiro in Brasilien ereignete sich 1988 ein Kondensatorbrand, bei dem etwa 150 Liter PCBs freigesetzt wurden. Es mußte befürchtet werden, daß ein Teil davon mit dem Löschwasser in den Rio Paraíba do Sul gelangt sein könnte, wo natürliche Schwebstoffe die schlecht wasserlöslichen PCBs bald adsorbieren. Da die feinen Trübstoffe sehr lange in der Schwebe bleiben, können hydrophobe (wasserabstoßende) Chemikalien wie die PCBs über weite Distanzen transportiert werden. In einem Fluß mit vielen Verzweigungen und Teilflüssen wird die durch eine ursprüngliche Stoßbelastung entstandene Schmutzstoffwelle flußabwärts über eine große Fließstrecke verteilt.

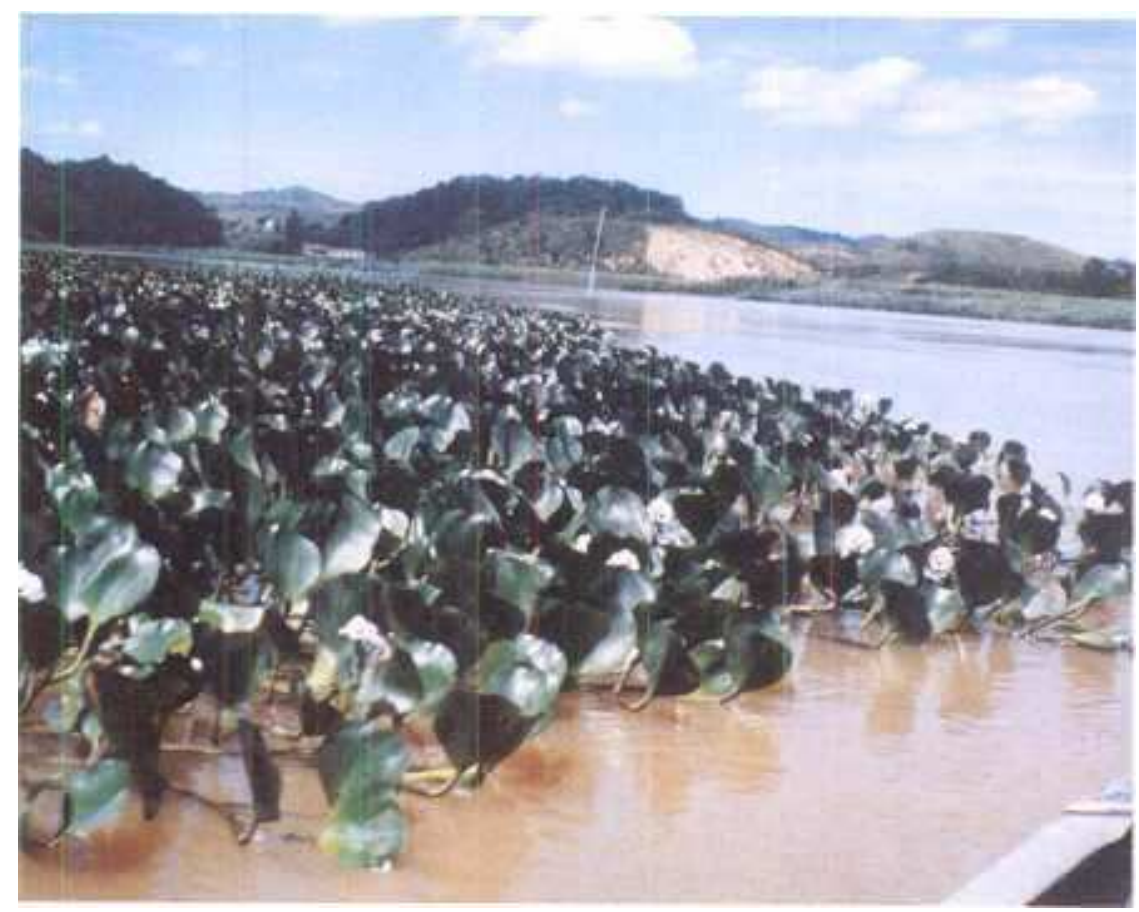

Figur 3. Ufervegetation des Rio Paraíba do Sul. Die physikalischen, chemischen und biochemischen Eigenschaften der PCBs bedingen ihre äußerst schlechte biologische Abbaubarkeit und eine starke Tendenz zur Anreicherung an Oberflächen und in den Fettphasen der aquatischen Organismen. Wegen dieser Konzentrationszunahme können PCBs in Gewässern zu problematischen Anreicherungen in Lebewesen führen, auch wenn sie nur in verschwindend kleinen Konzentrationen in der Wasserphase auftreten. 
globalen Ökosystemen verteilt (Figur 2). Auch der umgekehrte Vorgang, eine örtliche Ansammlung oder Bioakkumulation von PCBs, die vor allem auf ihren lipophilen Charakter zurückzuführen ist, wird beobachtet ${ }^{[8]}$ (Figur 3).

Tabelle 2 (siehe Seite 162) präsentiert eine Auswahl von PCB-Belastungen, die in verschiedenen Umweltkompartimenten gemessen wurden. Die Atmosphäre ist das dynamischste aller mobilen PCBReservoirs. Obwohl sie selbst nur einen kleinen Anteil der Gesamtmenge der mobilisierten PCBs enthält, ist sie ausschlaggebend für den Transport und den Austausch zwischen den verschiedenen globalen Reservoirs. Die durchschnittlichen atmosphärischen PCB-Konzentrationen über städtischen Gebieten sind viel höher als die über ländlichen $\mathrm{Ge}$ genden oder über dem Meer. Die belebte Natur, einschließlich Wildtiere, Haustiere, Menschen und speziell Pflanzen, enthält mehr PCBs als die oberste Schicht der Lithosphäre. Belastetes Oberflächenwasser, direkte Einleitung von kontaminierten Abwässern und atmosphärische Deposition tragen hauptsächlich zur PCB-Belastung der Hydrosphäre bei. Einzelne aquatische PCBReservoirs (Beispiele: Hudson River, New Bedford Harbor) können schwerwiegende lokale Probleme verursachen, auch wenn auf sie gemessen an der gesamten hydrosphärischen Belastung nur

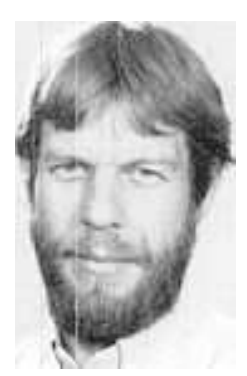

Hans-Peter E. Kohler: Geboren 1955 in Zürich.

Studium der Biochemie/Mikrobiologie an der ETH Zürich;

Promotion 1986 mit einer Arbeit über Essigsäurekatabolismus in Methanbakterien;

1986-1988 Post-doc an der University of California in

Riverside mit Arbeiten über aerobe PCB- und

Hydroxybiphenyl-Transformationen.

Heute als wissenschaftlicher Mitarbeiter an der EAWAG tätig;

befaßt sich hauptsächlich mit Biochemie, Physiologie und

Ökologie von Mikroorganismen mit Abbaupotential und mit

der Anwendung mathematischer Modelle in Mikrobiologie und

Biochemie.

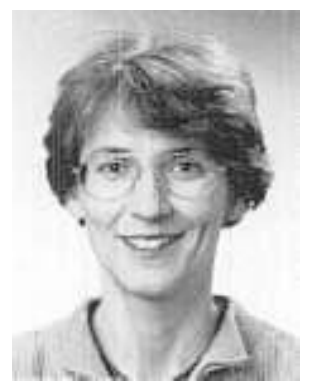

Doris Kohler-Staub: Geboren 1955 in Zürich.

Studium der Biochemie/Mikrobiologie an der ETH Zürich;

Promotion 1986 mit einer Arbeit über bakterielle

Dichlormethan-Dehalogenase;

1986-1988 Post-doc an der University of California in

Riverside mit Arbeiten über aerobe PCB-Transformationen und Abbau $\beta$-chlorierter aliphatischer Fettsäuren.

Heute als Oberassistentin in Lehre und Forschung an der ETH Zürich tätig;

befaßt sich hauptsächlich mit der Ausbildung von

Studierenden der Abteilung für Umweltnaturwissenschaften

in experimenteller Mikrobiologie.

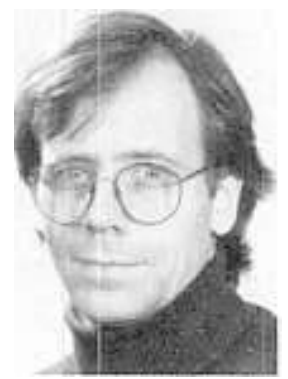

Alfredo C. Alder: Geboren 1952 in São Paulo, Brasilien. Studium der Mikrobiologie an der Universität Zürich; Promotion 1985 am Organisch-Chemischen Institut der Universitāt Zürich mit einer Arbeit über Pflanzenfarbstoffe; 1989-1990 Post-doc am New York University Medical Center mit Arbeiten über Dechlorierung von PCBs in anaeroben Sedimenten.

Seit 1986 Mitglied der Gruppe für organisch-chemische Analytik an der EAWAG; befaßt sich hauptsächlich mit dem Verhalten und Schicksal von organischen Chemikalien in der aquatischen Umwelt, insbesondere mit der

Erfassung mikrobiologischer Umwandlungsprozesse.

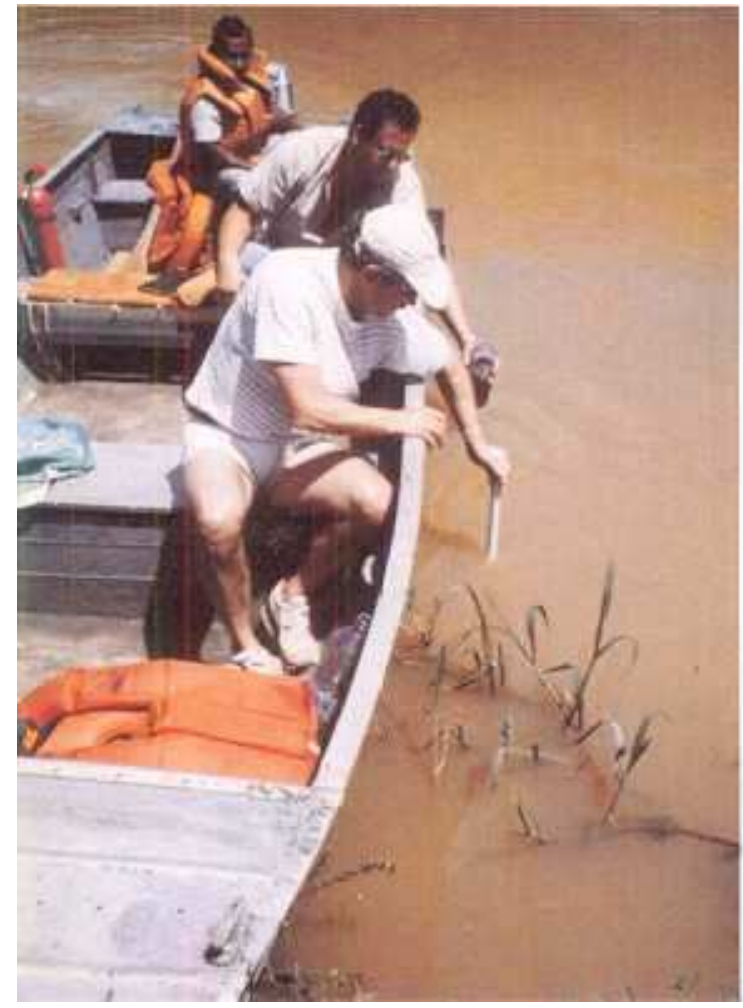

Figur 4. Probenahme für sedimentologische Untersuchungen. Für Aussagen über die mögliche Beeinträchtigung der Lebewesen in und an einem Fluß müssen auch die sedimentologischen Aspekte (Anteil und Charakteristik der im Wasser schwebenden Trübstoffe, zum Beispiel Korngrößenverteilung der Partikeln, Gehalt an organischem Kohlenstoff, Sedimentationsgeschwindigkeiten) berücksichtigt werden. Sedimente in Gewässern bilden wichtige Senken für schlecht wasserlösliche Umweltchemikalien (organische Stoffe, Schwermetalle) und haben eine große Bedeutung für die Beurteilung der bereits existierenden Grundbelastung eines Gewässers. In diesem Sinne können die Sedimente als das "Gedächtnis für die Verunreinigung eines Gewässers" aufgefaßt werden. ein kleiner Mengenanteil entfällt. Das Wasser der Ozeane enthält bei relativ niedrigen PCB-Konzentrationen die größte absolute Menge in den mobilen Reservoirs. PCBs in den Ozeanen stehen im Austausch mit PCBs in der Atmosphäre und mit PCBs in den Sedimenten. Obschon auch von dort ein langsamer Rücktransport möglich ist, stellen die Meeressedimente und Sedimente in groBen Seen die letzten "Senken" für PCBs dar (Figur 4). Im Gegensatz dazu verhalten sich Sedimente von Flüssen, Ästuarien und einigen Küstengebieten eher wie "Quellen" [9].

\section{Analytik von PCBs}

Die toxikologischen und biologischen Effekte von PCBs sind abhängig von der chemischen Struktur der jeweiligen Kongenere, respektive von der Kongenerenzusammensetzung im Falle von Gemischen. Um dieser Tatsache Rechnung zu tragen, versucht man heute sowohl kommerzielle Produkte wie auch aus der 
Umwelt oder aus biologischem Material extrahierte Proben mit kongener-spezifischen Methoden zu analysieren (Figur 5). Als Methode der Wahl bietet sich dazu hochauflösende Kapillar-Gaschromatographie mit Elektroneneinfang- (ECD) oder Massendetektion (MS) an. Auf diese
Weise gelang es, 187 der 209 existierenden Kongenere aufzutrennen ${ }^{[10]}$. Von sämtlichen 209 Kongeneren wurden die relativen Retentionszeiten und die relativen Responsfaktoren bestimmt. Die Kongenerenzusammensetzungen der kommerziellen Aroclor- und Clophen-

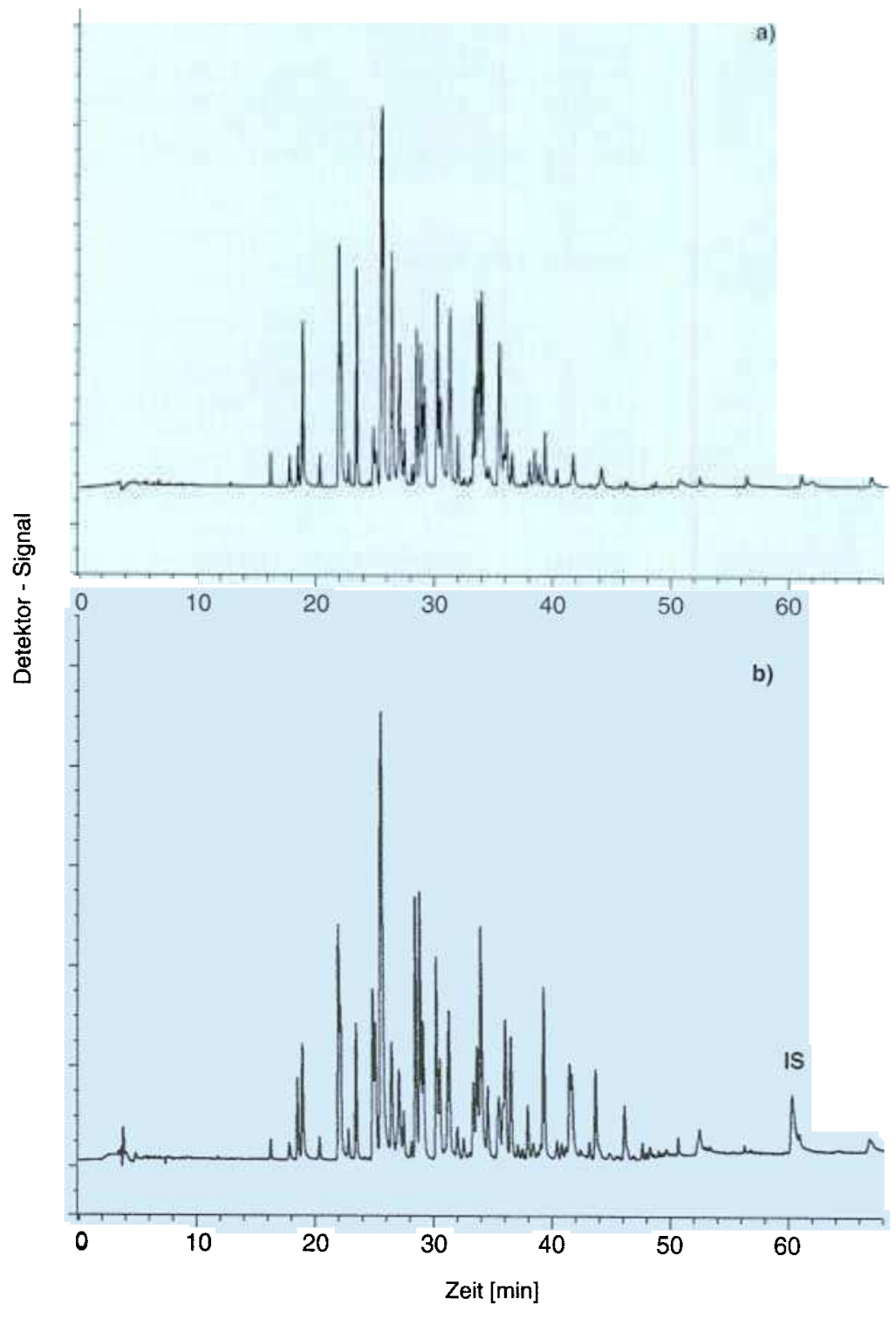

Figur 5. Hochauflösende Kapillar-Gaschromatographie: a) Chromatogramm von Aroclor 1242; b) Chromatogramm einer Kontamination (Arocior 1242 und 1254) eines Sediments aus New Bedford Harbor. IS: Interner Standard, Octachlornaphthalin. New Bedford Harbor liegt an der Mündung des Acushnet River, südlich von Boston, USA. Die Flußmündung wurde äußerst stark mit PCBs verschmutzt, welche zum größten Teil aus zwei industriellen Betrieben stammten, die PCB-haltige Abwässer direkt dorthin einleiteten. Die PCB-haltigen Sedimente sind ein anaerobes Milieu, in dem allfällige Umwandlungen ohne die Beteiligung von Sauerstoff geschehen.
Gemische konnte mit der KapillarGaschromatographie exakt bestimmt werden ${ }^{[11]}$.

\section{Umwandlungen von PCBs durch aerobe Mikroorganismen}

Mikroorganismen können in sauerstoffhaltiger Umgebung mehrfach chlorierte Biphenyle - ähnlich wie viele andere chlorierte Kohlenwasserstoffe praktisch nicht als Wachstumssubstrate verwerten. Doch diejenigen Bakterien, welche auf unchloriertem Biphenyl zu wachsen vermögen, bewirken an PCBs häufig gewisse chemische Umwandlungen, die sich sozusagen als Nebenerscheinungen parallel zum eigentlichen Stoffwechsel - als sogenannter Kometabolismus - ereignen. Unter Kometabolismus versteht man Stoffwechselvorgänge, bei denen chemische Verbindungen durch Bakterien partiell abgebaut, oxidiert oder sonstwie in ihrer molekularen Struktur verändert werden, ohne daß dabei Energie oder Bausteine zur Bildung von Zellmaterial gewonnen werden. Kometabolische Reaktionen können sowohl in sich vermehrenden Zellen als auch für eine begrenzte Zeitdauer in ruhenden, hungernden Zellen stattfinden ${ }^{[12]}$. Entscheidend für eine kometabolische Aktivität ist die Anwesenheit der dazu nötigen Enzyme, welche die Zellen in der Regel nur produzieren, wenn sie einen Bedarf dafür wahrnehmen. Im Falle der bakteriellen PCBTransformation beruhen die kometabolischen Prozesse auf der geringen Spezifität der biphenyl-oxidierenden Enzyme, die auch Oxidations-Reaktionen mit chlorierten Substratanalogen katalysieren (Figur 6). Diese Enzyme sind nur in solchen Zellen anwesend, die auf Biphenyl oder monochloriertem Biphenyl gezüchtet worden sind - ein Umstand, der vermutlich entscheidend zur Persistenz der PCBs in aeroben Umweltbereichen beiträgt.

Über Wachstum auf und Mineralisierung von monochlorierten Biphenylen durch Reinkulturen wurde berichtet ${ }^{[13]}$, aber es ist bisher noch keine Reinkultur isoliert worden, die zur vollständigen Mineralisierung von mehrfach chlorierten Biphenylen fähig ist. Noch gilt also der vorläufige Schluß, daß mit Ausnahme des monochlorierten Biphenyls alle übrigen PCBs durch Reinkulturen nur auf kometabolischem Wege und stets unvollständig abgebaut werden. Die Fähigkeit der Mikroorganismen, PCBKongenere kometabolisch umzuwandeln, 
variiert stark von Spezies zu Spezies ${ }^{[14]}$. Mit einer definierten Mischkultur aus einem Biphenyl- und einem 4-Chlorbenzoat-verwertenden Bakterium konnte erreicht werden, da $B$ in Gegenwart von Biphenyl als Wachstumssubstrat 4,4'Dichlorbiphenyl vollständig abgebaut wurde $^{[15]}$. In diesem Fall wurde 4,4'Dichlorbiphenyl durch Acinetobacter sp. Stamm P6 zuerst kometabolisch zu 4 Chlorbenzoat umgesetzt, worauf dieses ausgeschiedene Zwischenprodukt von Acinetobacter sp. Stamm 4CB1, dem zweiten Organismus des Konsortiums, als alleinige Kohlenstoff- und Energiequelle verwertet werden konnte. Mit der gleichen Kokultur wurde an 4,4'Dichlorbiphenyl die prinzipielle Möglichkeit des vollständigen Abbaus eines zweifach chlorierten Biphenyls in einem Bioreaktor demonstriert ${ }^{[16]}$.

Die Beobachtung, daß bakterieller Abbau und Transformationen von PCBs eng mit dem Biphenylstoffwechsel verknüpft sind, hat in jüngerer Zeit erneut das Interesse für die Biochemie des Abbaus dieses aromatischen Kohlenwasserstoffs geweckt. Die Reaktionssequenz des Biphenyl-Katabolismus (Figur 6) wurde schon anfangs der siebziger Jahre geklärt ${ }^{[17]}$. Obwohl die Biphenyl-Dioxygenase bisher nicht gereinigt werden konnte, gibt es Hinweise, $\mathrm{da} ß$ sie ähnlich funktioniert wie die genauer untersuchten Enzyme BenzolDioxygenase und Toluol-Dioxygenase. In beiden Fällen handelt es sich um Multienzymsysteme (Figur 7), welche die Oxidation des jeweiligen aromatischen Kohlenwasserstoffs zum cisDihydrodiol katalysieren ${ }^{[18]}$.

Bei der Suche nach Mikroorganismen mit PCB-Transformationsfähigkeit gelang es Ahmed und Focht ${ }^{[19]}$, erstmals zwei Organismen der Spezies Achromobacter mit Aktivität gegenüber verschiedenen Kongeneren auf Biphenyl und 4-Chlorbiphenyl zu isolieren. Seit 1972 wurde mit zahlreichen Studien belegt, daß in verschiedenen mikrobiellen Systemen (Anreicherungskulturen, Reinkulturen, natürliche Populationen) PCBTransformation - wenn auch vorwiegend mit Kongeneren niedrigen Chlorierungsgrades - tatsächlich stattfindet ${ }^{[14,20]}$. Erst in den letzten Jahren konnte nachgewiesen werden, daß auch kommerzielle PCB-Gemische, zum Beispiel Aroclor 1242 und 1254 mikrobiell verändert werden ${ }^{[21-24]}$.

Aus genauen Analysen der mikrobiellen Aktivitäten konnten Furukawa et al. ${ }^{[25]}$ einen Zusammenhang zwischen Kongenerenstruktur und Transformierbarkeit herleiten und aufgrund von Ex-
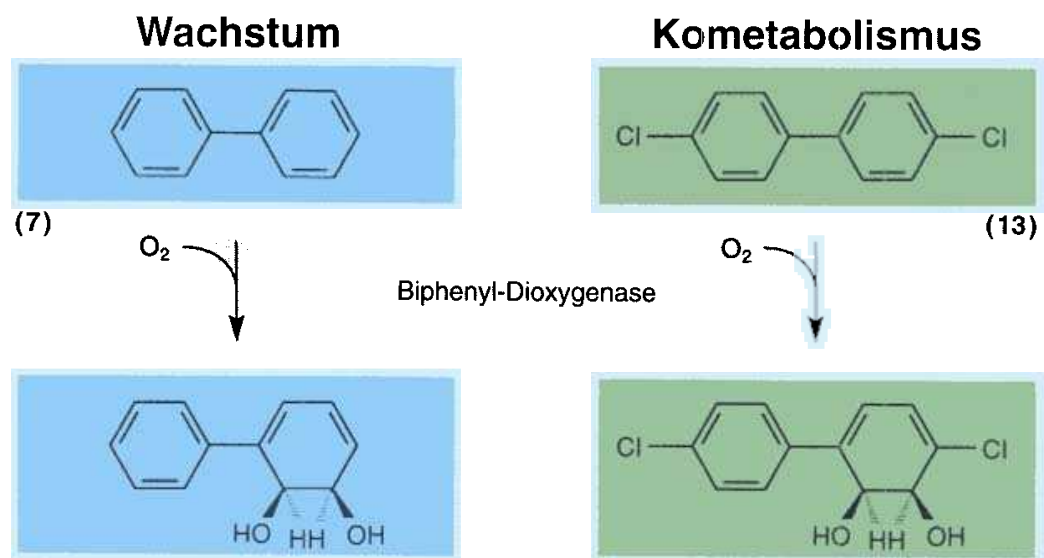

(8)

(14)
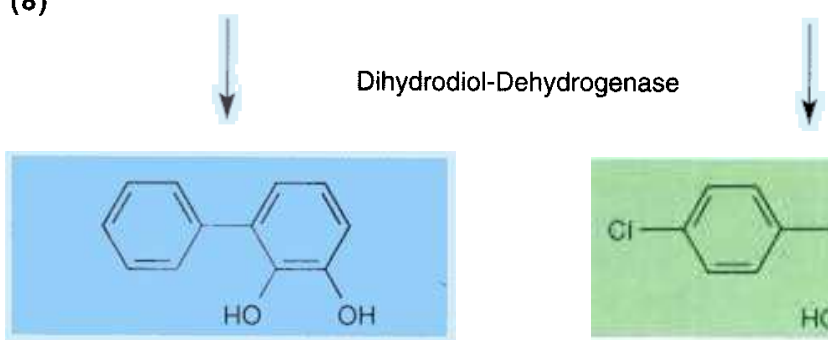

(9)
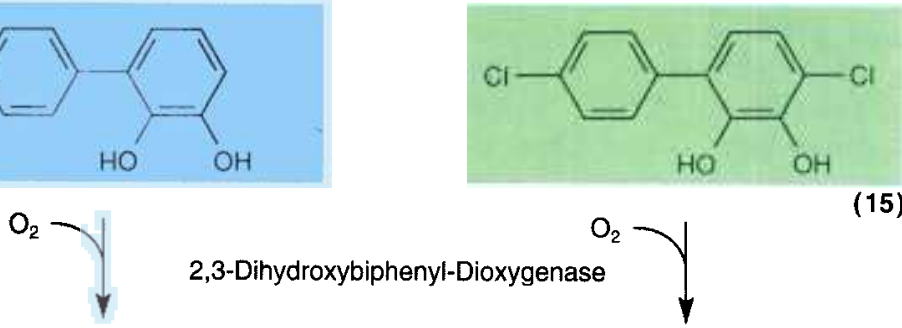

(15)

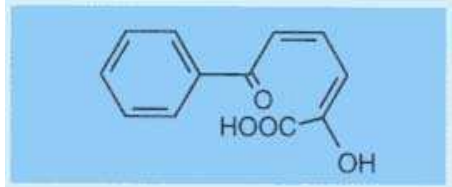

(10)
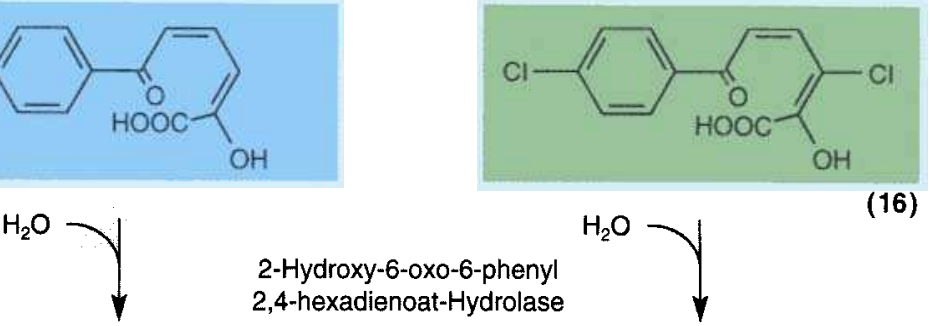

(16)
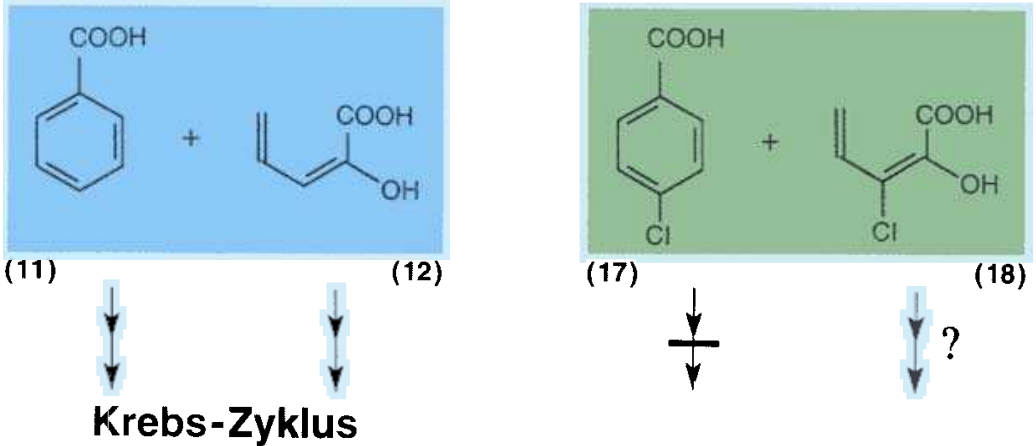

Figur 6. Metabolischer Abbauweg bei Wachstum von Mikroorganismen auf Biphenyl und kometabolische Transformationssequenz von 4,4'-Dichlorbiphenyl. Biphenyl (7) wird in 2,3-Stellung oxygeniert zu cis-Biphenyldihydrodiol (8), welches dann weiter zu 2,3Dihydroxybiphenyl (9) oxidiert wird. Diese Verbindung wird beim folgenden Umwandlungsschritt in 1,2-Stellung oxygeniert zu 2-Hydroxy-6-oxo-6-phenyl-2,4-hexadienoat (10), dem sogenannten meta-Spaltungsprodukt, das in einem weiteren Schritt zu Benzoesäure (11) und 2-Hydroxy-2,4-pentenoat (12) hydrolysiert wird. 4,4'-Dichlorbiphenyl (13) kann kometabolisch zu 4-Chlorbenzoesäure (17) umgewandelt werden. Die Verbindungen (14) bis (18) sind chlorierte Analoga der Metaboliten des Biphenylabbaus. Der schwarze Balken zeigt an, an welcher Stelle in vielen Fällen eine Blockade für weitere Umwandlungsprozesse besteht und somit derjenige Metabolit, der nicht mehr umgewandelt werden kann, angereichert wird. Bei höherchlorierten Kongeneren kann sich die Blockade weiter oben in der Reaktionssequenz befinden, so daß verschiedenartige Metaboliten, über deren Toxizität und Umweltverhalten wenig bekannt ist, angereichert werden können. 
perimenten mit den beiden Organismen Alcaligenes sp. Stamm Y42 und Acinetobacter sp. Stamm P6 folgende Regeln aufstellen:

1. Mit zunehmendem Chlorgehalt werden die PCB-Kongenere schlechter transformiert.

2. Kongenere mit zwei ortho-Chloratomen an einem Phenylring (in 2,6Stellung) oder an jedem der beiden Ringe (in 2,2'-Stellung) sind sehr resistent gegenüber mikrobiellen Angriffen.

3. Kongenere, welche alle Chloratome an einem Ring enthalten, werden gewöhnlich schneller metabolisiert als solche, bei denen die gleiche Anzahl Chloratome über beide Ringe verteilt ist.

Untersucht wurde auch die Produktbildung bei der Transformation von 36 reinen Kongeneren und von verschiedenen Kaneclor-Typen (industrielle PCBProdukte) ${ }^{[23,26,27]}$. Der Nachweis sämtlicher chlorierter Metaboliten, (13) bis (17), bestätigte, daß PCBs hauptsächlich nach der in Figur 6 angegebenen $\mathrm{Re}$ aktionsabfolge umgewandelt werden. Verschiedene Kongenere werden jedoch in unterschiedlichem Ausmaß metabolisiert, sowohl bezüglich des mengenmäßigen Umsatzes als auch der Anzahl von Reaktionsschritten. Außerdem entstehen zusätzliche Nebenprodukte, die keinem der Zwischenprodukte der in Figur 6 dargestellten Abbausequenz entsprechen, vor allem Monohydroxy- und
Trihydroxyderivate. Angesichts der Tatsache, daß die kommerziellen PCBProdukte aus bis zu 70 Kongeneren bestehen und daß bei mikrobiellen Transformationen pro Kongener bis zu 6 verschiedene Verbindungen als Endprodukte auftreten können, erstaunt es nicht, wenn über die Zusammensetzung der Transformationsprodukte noch keine exakten Kenntnisse vorhanden sind.

Studien über das Schicksal von Aroclor 1242 in Bodenproben ergaben, $\mathrm{da}$ es beim PCB-Abbau in Böden auf zwei Voraussetzungen ankommt [24, 28]: Erstens müssen sich in der ansässigen Population zur PCB-Transformation fähige Mikroorganismen befinden, und zweitens darf deren Anzahl ein gewisses Minimum nicht unterschreiten. Erst bei einer gezielten Anreicherung abbaufähiger Organismen durch Zugabe des strukturanalogen, verwertbaren Kohlenwasserstoffs Biphenyl wurde überhaupt eine signifikante Mineralisation von Aroclor 1242 erreicht ${ }^{[24]}$. In einem solchen Experiment konnten nach einer Inkubationsdauer von 63 Tagen 20-27\% des vorgelegten radioaktiven Aroclors 1242 als ${ }^{14} \mathrm{CO}_{2}$ aufgefangen werden, während im Kontrollversuch ohne Biphenyl-Zugabe weniger als $1 \%$ $\mathrm{zu}{ }^{14} \mathrm{CO}_{2}$ umgesetzt wurde. Inokulation mit Acinetobacter sp. Stamm P6 bewirkte nur bei gleichzeitiger Zugabe von Biphenyl eine Steigerung der Abbaurate.
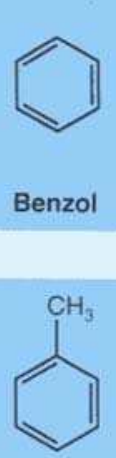

Toluol

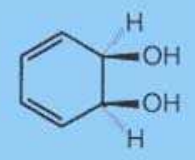

cis-Dihydrobenzol-diol

cis-Dihydrotolual-diol
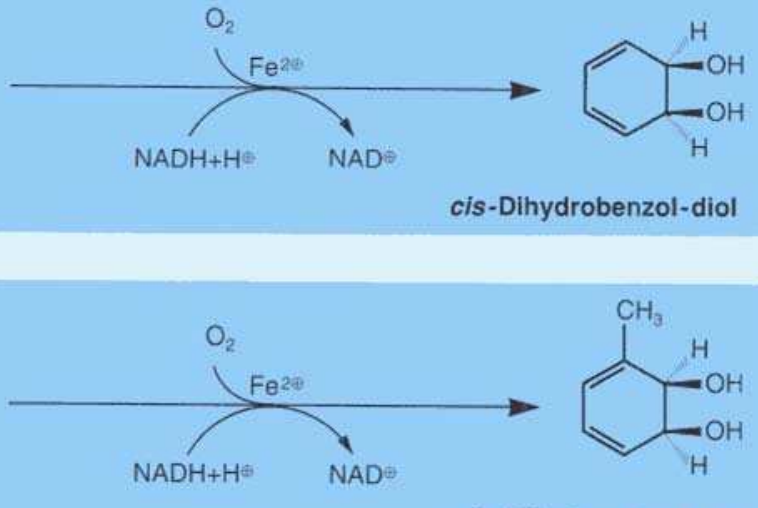

Figur 7. Enzymreaktionen, die durch Benzol- und Toluol-Dioxygenase katalysiert werden. Beides sind Multienzymkomplexe, welche aus drei Enzymen bestehen: einem Flavoprotein und zwei Eisen-Schwefel-Proteinen.
Daraus wurde geschlossen, daß in den Bodenproben eine ansässige PCBtransformierende Mikroorganismenpopulation vorhanden war, die sich dem Spezialisten Acinetobacter sp. Stamm P6 im Transformationsvermögen unterlegen erwies und erst durch Zugabe von Biphenyl vermehren konnte.

Zellen, welche aktiv auf Biphenyl wachsen, vermögen PCBs in einem viel größeren Ausmaß zu kometabolisieren als ruhende Zellsuspensionen. Dies geht aus einer Untersuchung über das Transformationsvermögen von Acinetobacter sp. Stamm P6 und Arthrobacter sp. Stamm B1B gegenüber Aroclor 1254 hervor ${ }^{[22]}$ : Wachsende Zellen wandelten $32 \%$ beziehungsweise $23 \%$ des $\left[{ }^{14} \mathrm{C}\right]-$ Aroclors 1254 um, ruhende Zellen nur $17 \%$ beziehungsweise $8 \%$. Zudem stellte sich heraus, daß Acinetobacter sp. Stamm P6 einer der vielseitigsten PCB-transformierenden Organismen ist, da er 25 der 40 wichtigsten Komponenten von Aroclor 1254 mit seinem Kometabolismus erfaßte. Dabei wurden auch Kongenere umgewandelt, deren 2,3Stellungen dem postulierten Dioxygenase-Angriff nicht offenstehen [27].

Inwieweit hydroxylierte PCBs, wie sie bei der kometabolischen Transformation von PCBs entstehen, weiter umgewandelt werden, ist zur Zeit noch unklar. Pseudomonas sp. Stamm HBP1 kann 2-Hydroxybiphenyl als alleinige Kohlenstoff- und Energiequelle nutzen. Dabei wird 2-Hydroxybiphenyl durch eine NADH-abhängige Monooxygenase $\mathrm{zu}$ 2,3-Dihydroxybiphenyl (9) umgesetzt, das dann entsprechend dem Abbauweg für Biphenyl (Figur 6) metabolisiert wird. 2,2'-Dihydroxybiphenyl wird $\mathrm{zu}$ 2,2',3-Trihydroxybiphenyl umgesetzt und ergibt über den gleichen Abbauweg schließlich 2-Hydroxybenzoat (Salicylat). Chlorierte Hydroxybiphenyle dienten der Monooxygenase hingegen nur als Pseudosubstrate, das heißt, NADH und Sauerstoff wurden verbraucht ohne gleichzeitige Hydroxylierung des Substrats ${ }^{[29]}$. Nach diesen Befunden ist es unwahrscheinlich, daß HydroxybiphenylAbbauer auf hydroxylierten PCBs wachsen können. $\mathrm{Ob}$ andere Stämme im Unterschied zum erwähnten Organismus - solche Verbindungen wenigstens kometabolisch zu transformieren vermögen, ist eine offene Frage.

Chlorierte Benzoesäuren und ungesättigte chlorierte Carbonsäuren können als Produkte der kometabolischen Tätigkeit von PCB-transformierenden Organismen auftreten (Figur 6). Der Abbau chlorierter Benzoesäuren, welche zum Teil als alleinige Kohlenstoff- und 
Energiequelle von manchen Organismen genutzt werden ${ }^{[30]}$, sei hier nicht weiter erörtert. Wie Untersuchungen an Chlorcrotonsäure zeigen, werden ungesättigte $\beta$-chlorierte aliphatische Carbonsäuren durch $\beta$-Oxidation abgebaut, wobei die Dechlorierung auf der Stufe des Coenzym A-Derivates einsetzt ${ }^{[31]}$.

\section{Genetikderaeroben mikrobiellenPCB-Transformation}

Da bis heute keine spezifischen, andere Substrate diskriminierenden Enzyme für den PCB-Abbau gefunden werden konnten, wird vorerst angenommen, $\mathrm{da}$ sämtliche aeroben Stoffwechselreaktionen mit PCBs von den Enzymen des Biphenylkatabolismus abhängen. Nachdem diese Enzyme identifiziert worden waren, galt das Interesse der dafür codierenden genetischen Vorlage, ihrer Organisation, ihrer Regulation und ihren molekularen Eigenschaften. Mit der Frage nach der Evolution und Verbreitung dieses Genotyps beschäftigt man sich in zahlreichen Laboratorien.

Die vier Enzyme Biphenyl-Dioxygenase, Dihydrodiol-Dehydrogenase, 2,3-Dihydroxybiphenyl-Dioxygenase und 2-Hydroxy-6-oxo-6-phenyl-2,4 hexa-dienoat-Hydrolase (Figur 6) werden durch die Gene $b p h A, B, C$ und $D$ codiert. Bei den Organismen Pseudomonas pseudoalcaligenes KF707 [32], Pseudomonas putida KF715 ${ }^{[33]}$, Pseudomonas sp. Stamm LB400 ${ }^{[34]}$, Pseudomonas testosteroni Stamm B356 ${ }^{[35]}$ und Pseudomonas putida OU83 [36] gelang die Isolierung von ungefähr 9000 Nucleotidbasen langen chromosomalen DNAFragmenten, welche die gesamte für die Oxidation von Biphenyl zu Benzoat nötige Information enthalten. Die Strukturgene sind auf dem Chromosom in der Reihenfolge $b p h A, b p h B, b p h C$, $b p h D$ angeordnet. Obwohl gegenwärtig noch wenig über die Regulation der Expression dieser vier Gene bekannt ist, steht doch fest, daß sie in einem einzigen Operon organisiert und somit einem gemeinsamen Kontrollmechanismus unterworfen sind. Bei den Organismen Alcaligenes sp. Stamm A2 und Acinetobacter sp. Stamm A8, die beide fähig sind, 4-Chlorbiphenyl vollständig $\mathrm{zu}$ mineralisieren, ist dieses Abbauvermögen auf einem Plasmid codiert ${ }^{[14]}$.

Der Ähnlichkeitsgrad zwischen den für den Biphenylabbau codierenden Strukturgenen wurde durch Vergleich der Größen und der Restriktionsprofile der klonierten DNA-Fragmente erfaßt. In

\section{Exkurs: Toxische Wirkungen von PCBs}

Wahrend des siebziger Jahre wurde in zahlreichen Tierversuchen die Wirkung von PCBs aut die Gesundheit hoherer Lebewesen untersucht, vorwiegend mit technischen PCB-Produkten, welche je nach Hersteller und Chlorierungsgrad seh unterschiedliche Zusammensetzung aufweisen, Dabei wurde nicht berücksichtigt, daß solche Gemische stets kleine Anteile hochtoxischer Verunreinigungen enthaiten, zum. Beispiel polychlarierte Dibenzofurane (6) und Dibenzodioxine ( 5 ; siehe Figur 1). Nach Erkennen dieses Problems wurden in den achtziger Jahren weitere toxikologische Untersuchungen mit einzelnen PCB-Kongeneren durchgetührt, die zeigten, daß deren toxische Wirkung stark variert und von der spezifischen Molekülstruktur abhangt.

Bei einer einmaligen Verabreichung schwankt die mittlere tódliche Dosis (LD) der technischen PCB-Produkte sowie einzelner Kongenere in weiten Grenzen: Die LD:Werte füt Fatten und Kaninchen varieren im Falle von Aroclor-Produkten zwischen 1 und 11 g/kg Körpergewicht beziehungsweise zwischen 1 und $3 \mathrm{~g} / \mathrm{kg}$ Körpergewicht. Für Meerschweinchen, die generell empfindlicher reagieren, betrăgt mit $3,3^{\prime}, 4,4 ;, 5,5^{\prime}$-Hexachlorbiphenyl der LQ-Wert $0.5 \mathrm{mg} / \mathrm{kg}$ Korpergewicht und mit $2,2,4,4,6,6$-Hexachlorbiphenyl $64 \mathrm{mg} / \mathrm{kg}$ Kömergewicht. Diese unterschiedliche Wirkurg zweier Kongenere mit der gleichen Anzahl Chloratome fehrte zur Frage nach der Strukturabhângigkeit der PCB-Toxizitat. Wichtig scheint die räumliche Anordung der beiden Phenylringe zu sein, die durch die Stellung der Chilorsubstituenten bestimmt wird. In Abwesenheit von Substituenten in ortho-Stellung ist Koplanarităt, das heiß̉t die Lage von beiden Ringen in einer Ebene, moglich. PCB-Molekule erhalten in der koplanaren Konformation ähnliche sterische Eigenschaften wie die bekanntlich hochtoxischen polychlotierten Dibenzodioxine (zum Beispiel 2,3,7,8-Tetrachlordibenzodioxin (5)), deren Planarität fixiert ist. Neben einer direkten Toxizität scheint die Wirkungsweise der koplanaren Kongenere wie bei den polychlorierten Dibenzodioxinen auf der Induktion von fremdstoff-metabolisierenden, Cytochrom-P-450-abhängigen Monooxygenasen zu beruhen. In einem ersten Schritt reagieren diese sterisch ăhnlichen Verbindungen möglicherweise alle mit dem gleichen Rezeptor in der Zelle, dem sogenannten Ah-Rezeptor, welcher mit planaren aromatischen Molekülen einen Komplex bilden kann. Dieser Komplex wird in den Zellkorn eingeschleust und bepinilußt dort die Expression bestimmter Gene. Die dabei induzierten Monooxygenasen bewirken ihrerseits eine Aktivierung fremdartiger, ursprünglich richt tox scher Vorbindungen, die in cytotoxische oder: genotoxische Metaboliten umgewandelt werden.

Durch Tierversuche wurde festgestellt, in welchen Storungen und Schäden sich die toxischen Wirkungen von PCB.Produkten und einzelnen Kongeneren manifestieren. Bei einer langfristigen täglichen Verabreichung von PCB-Produkten mit dem Futter lagen die NOEL (no effect level)-Werte für Ratteri. Mause und Rhesusaffen bei $0.25-5 \mathrm{mg} / \mathrm{kg}$ Körpergewicht. Hōhere Dosen führten zu Gewichtsverlust und Veränderungen an verschiedenen Organen, vor allem an der Leber und der Haut. PCBs kónnen die Placenta passieren, haben aber nur in Einzelfälien Mißbildungen hervorgerufen. Cancerogenitāt konnte nie eindeutig nachgewiesen werden, jedoch wird angenommen, daß PCBs Tumorbildung zwar nicht auslösen, aber unterstützen. Wărend die Wirkung auf die zellabhangige Immunität gering erscheint, ist die Verminderung der humoralen Immunität signifikant: die flesistenz gegen Infektionen war vermindert, nachdem $100 \mathrm{mg}$ Aroclor 1254 pro kg Futter wahrend mehrerer Wochen verabreicht wurden.

Beobachtungen beim Menschen wurden vor al em nach zwei Massenvergiftungen durch den Verzehr von PCB-haltigem Reisōl, 1968 in Japan und 1979 in Taiwan, gemacht. Die Aus. wirkungen und Symptome wie Schwächegefül, Sehschwãche, Taubheit der Extremitaten. Kopfschmerzen, andauernde Hautveränderungen (Chlorakne), Haarausfall mussen jedoch zum Teil den die PCBs (430 mg/L Ö) begleitenden polychlorierten Dibenzofuranen (3.9 mg/L Ol) zugeschrieben werden. Mehrere PCB-Kongenere können bekanntlich in Frauenmilch nachgewiesen werden. Eine Wirkung dieser PCEs auf Săuqlinge ist aber nicht bekannt.

Der EintluB der sich in der Umwelt befindlichen PCBs aut ganze Okosysteme, das heiß auf die Zusammensetzung und den Gesundheitszustand ihrer ansássigen Lebensgemeinschaften, ist weit schwieriger zu ermitteln als die durch kontrollierte Verabreichung hervargerufenen Effekte auf einzelne Lebewesen. Schon alein die Tatsache, daß in der Umwelt Transportvorgănge und biologische Umwandlungsprozesse die ursprüngliche Zusammensetzung der technischen PCB-Gemische fortlaufend verándem, erschwert den Nachweis, daß eine beobachtete Storung tatsachlich und ausschließlich wegen PCB.Einträgen eingetreten ist. Ein fûr die Okotoxikologie von PCBs wichtiges Phânomen sind der Transport und die Konzentrationsverschiebungen innerhalb der Biozönose selbst über die Nahrungskette; die PCB-Anreicherung im Fettgewebe führt zu Spitzenkonzentrationen bei den Mitgliedem am Ende der Nahrungskette (Fische, Vögel und Säugetiere). Der Rückgang der Fischotterpopulationen in Europa könnte im Zusammenhang mit einer zunehmenden PCB-Anreicherung in den Fischen - der Nahrungsgrundlage der Fischotter - stehen.

Weiterführende Literatur: V. A. McFarland, J. U. Clarke: "Environmental occurrence, abundance, and potential toxicity of polychlorinated biphenyl congeners: Considerations for a congener-specific analysis", Environmental Health Perspectives 81 (1989) 225-239; A. Parkinson, S. Safe: "Mammalian biologic and toxic effects of PCBs", in S. Safe, O. Hutzinger (Ed.): Polychlorinated Biphenyls (PCBs): Mammalian and Environmentaf Toxicology, Springer-Verlag. Berlin (1987), p. 49-75: siehe auch Ret. [7] und [8]. 
einigen Fällen liegen für gewisse $\mathrm{Ab}$ schnitte des Operons bereits die Nucleotid-Sequenzen vor. Überdies haben Hybridisierungsexperimente, bei denen Gesamt-DNA aus einer Vielzahl von biphenyl-abbauenden Stämmen mit aus klonierten Biphenyl-Genen bestehenden DNA-Sonden getestet wurde, AufschluB über das Ausmaß der DNA-SequenzHomologie bei diesen Stoffwechselgenen ermöglicht. Die Summe aller molekulargenetischen Untersuchungen ergibt ein interessantes Bild: Zum einen können Mikroorganismen mit PCB-Transformationsfähigkeit mindestens drei genotypisch deutlich unterscheidbaren Gruppen zugeordnet werden. Zum andern scheinen innerhalb einer Gruppe die betreffenden Strukturgene sehr ähnlich, möglicherweise sogar identisch zu sein. $\mathrm{Da}$ die Organismen selbst ansonsten keine nahe Verwandtschaft zeigen, wird vermutet, daB sich die genetische Information für den Biphenyl/PCB-Abbau auch horizontal - das heißt, nicht nur bei einer Zellteilung von Mutter- auf Tochterzellen, sondern auch durch Übertragung von DNA-Stücken in "fremde" Bakterienzellen - verbreitet hat.

Die aus klonierten Biphenyl/PCBAbbau-Genen hergestellten selektiven DNA-Sonden finden im Zusammenhang mit dem Nachweis von PCB-transformierenden Mikroorganismen in der Umwelt eine zusätzliche Anwendung. Um die Abbaukapazität der anwesenden Populationen abzuschätzen, kann Erdmaterial, das mit PCBs verschmutzt ist, mit diesen Sonden bezïglich Anzahl und Diversität solcher Organismen getestet werden ${ }^{[37]}$.

\section{Umwandlungen von PCBs durch anaerobe Mikroorganismen}

Brown et al. ${ }^{[38,39]}$ berichteten, daß die PCB-Kongenerenverteilung in Sedimenten des Hudson River (New York) sowie des Silver Lake (Massachusetts) nicht der ursprünglichen KongenerenZusammensetzung des dort ausgeflossenen Aroclors entsprach, sondern im sauerstofffreien Milieu offenbar die chlorärmeren ortho-substituierten Kongenere angereichert wurden. Sie schlossen daraus, da $B$ in diesen Sedimenten eine anaerobe, reduktive Dechlorierung von PCBs stattfand - ein Vorgang, bei dem Chloratome gegen Wasserstoffatome ausgetauscht werden. Diese Deutung wurde aber zunächst in Frage gestellt [40] mit dem Argument, die beobachtete Kongenerenverteilung könne plausibler als selektive Anreicherung einzelner Kongenere aufgrund ihrer chemischen und physikalischen Eigenschaften erklärt werden.

Die prinzipielle Möglichkeit der reduktiven Dechlorierung von PCBs konnte erst von Quensen et al. ${ }^{[41,42]}$ durch Versuche im Laboratorium verifiziert werden. Unter methanogenen Bedingungen erfolgte die Dechlorierung von Aroclor 1242 in kontaminierten Sedimenten aus dem Hudson River (historische Kontamination mit Aroclor 1242) bevorzugt in para- und meta-Stellung bei gleichzeitiger Anreicherung von ortho-substituierten Kongeneren. So wurden bei einer Inkubationsdauer von 12 Wochen $85 \%$ der meta- und paraChloratome entfernt. Die Mikroorganismen einer Sedimentprobe aus dem Silver Lake (historische Kontamination mit Aroclor 1260) dechlorierten neu zugegebenes Aroclor 1260 bei einer Inkubationsdauer von 16 Wochen in para- und meta-Stellung, die metaChloratome wurden bevorzugt entfernt. Eine vollständige Dechlorierung von Sedimenten zugegebenen PCBs zu Biphenyl konnte bisher noch nicht beobachtet werden.

In weiteren Untersuchungen an Sedimenten des Hudson River and Silver Lake wurden vier kommerzielle PCBProdukte (Aroclor 1242, 1248, 1254 und 1260) in verschiedenem Ausma 3 durch Mikroorganismen reduktiv dechloriert ${ }^{[42]}$. Das Ausmaß und die Geschwindigkeit der Dechlorierung nehmen bei höherem Chlorierungsgrad ab, obwohl sich das Reduktionspotential von PCBs mit der Anzahl der Chloratome erhöht ${ }^{[43]}$.

Ein Vergleich von Dechlorierungsmustern in den verschiedenen Sedimenten läßt auf die Existenz von Organismen mit unterschiedlichen Dechlorierungsfähigkeiten schließen: Mikroorganismen im Sediment des Hudson River zeigten sich zum Beispiel beim Entfernen der letzten para-Chloratome ihren Konkurrenten vom Silver Lake überlegen ${ }^{[42]}$. Offenbar prägt die Geschichte der PCB-Kontamination in den Sedimenten die selektive Anreicherung bestimmter Organismen.

So verschiedene organische Substrate wie Methanol, Glucose, Aceton oder niedermolekulare Fettsäuren eignen sich als Quelle der für die Dechlorierung benötigten Elektronen ${ }^{[44,45]}$. Die Geschwindigkeit und das Ausmaß der Dechlorierung werden - wenigstens in Sedimenten mit einem mäßigen Gehalt an abbaubarem Kohlenstoff - durch Zugabe solcher Substrate beträchtlich gesteigert. Dies weist darauf hin, daß die Bioverfügbarkeit reduzierter Substrate für die Dechlorierung der PCBs in Sedimenten ein limitierender Faktor ist.

Reduktive Dechlorierungen werden begünstigt durch stark reduzierende Milieu-Bedingungen. Unseres Wissens ist die Dechlorierung von PCBs nur unter methanogenen, nicht aber unter sulfatreduzierenden Bedingungen beobachtet worden.

Bei einer der seltenen Untersuchungen über das Verhalten spezieller Kongenere gelang erstmals der Nachweis einer anaeroben Dechlorierung in orthoStellung ${ }^{[46]}$. 2,3,5,6-Tetrachlorbiphenyl wurde innerhalb von 37 Wochen $\mathrm{zu}$ 2,5-Di- (21\%), 2,6-Di- (63\%) und 2,3,6Trichlorbiphenyl (16\%) umgewandelt.

Der Unterschied zwischen dem, was mit bereits vorhandenen PCBs, und dem, was mit frisch zugegebenen PCBs in den Sedimenten geschieht, ist bemerkenswert. Während frisch zugegebenes Aroclor ohne weiteres dechloriert wurde, konnte gleiches für PCBs "in situ" nicht immer festgestellt werden ${ }^{[45]}$. In Sedimenten des Hudson River wurden bereits umgewandelte PCBs nicht weiter dechloriert. Auch wurde in Sedimenten des Silver Lake keine Dechlorierung des ursprünglichen Aroclor 1260 beobachtet. Anderseits ergaben Sedimente aus New Bedford Harbor (Massachusetts) für schon vorhandene und frisch zugegebene PCBs ähnliche Dechlorierungs-

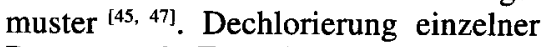
Penta- und Tetrachlorbiphenyle bei gleichzeitiger Anreicherung von Di-, Triund Tetrachlorbiphenylen wurde beobachtet; Monochlorbiphenyle fehlten unter den Produkten. Die Gesamtrate der Dechlorierung in den Sedimenten von New Bedford Harbor war kleiner als in den Sedimenten des Hudson River. Das bestätigt die Vermutung, daß die unterschiedliche Bioverfügbarkeit von PCBs in der Sediment-Matrix ein maßgeblicher Faktor sein könnte. Weitere Gründe könnten unterschiedliche mikrobielle Populationen oder Inhibition durch gelöste Stoffe wie Metallionen und Sulfat sein. Auch sind die übriggebliebenen, zumeist ortho-substituierten Kongenere (wie im Sediment des Hudson River) wahrscheinlich persistent gegenüber Dechlorierung unter anaeroben Bedingungen.

Reduktive Dechlorierung in mit PCBs kontaminierten Sedimenten deutet darauf hin, daß eine Anreicherung von dechlorierenden Organismen vorausging. Eine Hypothese erklärt diese Anreicherung mit einem Selektions- 
vorteil für jene Organismen, die imstande sind, PCBs als terminalen Elektronenacceptor $\mathrm{zu}$ verwenden und/oder die potentiell vorhandene Energie aus der Dechlorierungsreaktion zu nutzen ${ }^{\text {[42] }}$. Dies stimmt mit der Beobachtung überein, daß die Dechlorierung von PCBs stark von der Konzentration abhängig ist ${ }^{[41]}$. Die größte Dechlorierungsrate wurde bei Zugabe von $700 \mathrm{ppm}$ Aroclor 1242 gemessen (innerhalb von 16 Wochen wurden $53 \%$ der Chloratome entfernt). Die Rate war deutlich kleiner bei Zugabe von $140 \mathrm{ppm}$, und bei Zugabe von $14 \mathrm{ppm}$ konnte keine Dechlorierung mehr festgestellt werden.

In anaeroben Habitaten kann das Fehlen von genügend Elektronenacceptoren für den Stoffwechsel hinderlich sein. Deshalb hätte jeder Organismus, der PCBs als Elektronenacceptor benützen kann, in der Tat einen Selektionsvorteil $^{[39]}$. Allerdings ist über die beteiligten Organismen und Dechlorierungsmechanismen bis heute wenig bekannt.

\section{Ausblick}

Es liegt auf der Hand, daß die gegenwärtigen und zukünftigen Untersuchungen über die Wechselwirkungen zwischen Mikroorganismen und PCBs im Zusammenhang stehen mit dem dringlichen Bedarf für Strategien zur Entsorgung von Restbeständen an PCBs oder zur Reinigung von PCB-kontaminierten Umweltkompartimenten.

Der heutige Stand des Wissens erlaubt in groben Umrissen eine Beurteilung der Rolle von biologischen Prozessen beim langfristigen, nicht manipulierten oder kurzfristigen, durch gezielte Maßnahmen unterstützten Abbau von PCBs. Die offenbar widersprüchlichen Beobachtungen der extremen Persistenz von PCBs in allen möglichen Ökosystemen einerseits und der in relativ hohen Raten erfolgenden mikrobiellen Abbau- und Umwandlungsvorgänge in Laborversuchen anderseits lassen sich heute weitgehend erklären: Die bakteriellen Stoffwechselleistungen sind abhängig von verschiedenen, die chemisch-physikalischen und morphologischen Milieueigenschaften betreffenden Faktoren, beispielsweise von Bioverfügbarkeit oder Redoxverhältnissen.

Die Wahrscheinlichkeit dafür, daß eine Bakterienzelle mit PCB-Molekülen in Berührung kommt und diese ins Zellinnere aufnimmt, hängt davon $a b$, wie stark räumliche Barrieren und Wechselwirkungen mit anderen Stoffen dem
Tabelle 2. PCB-Vorkommen in Abwasser, Gewässern, Trinkwasser, Luft und Boden.

\begin{tabular}{|c|c|c|c|}
\hline Probe & Ort/Land & Konzentration & Literatur \\
\hline $\begin{array}{l}\text { Abwasser } \\
\text { ungereinigt } \\
\text { mechanisch gereinigt } \\
\text { biologisch gereinigt }\end{array}$ & $\begin{array}{l}\text { Schweiz } \\
\text { Schweiz } \\
\text { Schweiz }\end{array}$ & & $\begin{array}{l}{[48]} \\
{[61]} \\
{[48]}\end{array}$ \\
\hline
\end{tabular}

Klärschlamm

Wasser in Gewässern

Rhein

Ober-

Mittel- / Nieder-

$\mu \mathrm{g} / \mathrm{L}$

Main

Rio del Plata

Kanal

Hudson River

Mündung

$0.001-0.009$

$0.012-0.060$

$0.066-0.110$

$0.020-0.057$

$0.007-0.027$

0.53

$0.05-0.10$

[50]

[50]

[50]

[51]

Bodensee

Zürichsee

Lake Superior

$0.001-0.009$

$0.001-0.010$

0.0005

[50]

[50]

Sedimente in Gewässern

Rhein

Rio del Plata

Kanal

Hudson River

Mündung

USA

Oberflächensediment

$15-30 \mathrm{~cm}$ unterhalb der

Oberfläche

New Bedford Harbor

USA

Acunshet Estuary, New Bedford

USA

$\mu \mathrm{g} / \mathrm{g}$ TS

$0.03-4.8$

$0.002-1.0$

$0.002-0.043$

$7-35$

$>700$

1000

[54]

Regen

Great Lakes

Lake Michigan

New York State

Fribourg, Biel

Kiel

USA

USA

USA

Schweiz

Deutschland

[55]

[51]

Nebel

Zürich

15-33

300

$0.6-3.7 \cdot 10^{3}$

[56]

[57]

[58]

$\mu \mathrm{g} / \mathrm{L}$

$0.010-0.100$

0.005-0.05

1.3

$0.010-0.052$

$0.0005-0.005$

[60]

[52]

[61]

$\mu \mathrm{g} / \mathrm{L}$

11

[63]

Trinkwasser

New York State

$\mu \mathrm{g} / \mathrm{L}$

$0.069-0.1$

[52]

Ozeane

$\mathrm{ng} / \mathrm{L}$

$0.01-0.5$

Luft

Kiel BRD

Lake Superior USA

Bloomington USA

Antarktis

untere Troposphäre

$\mathrm{ng} / \mathrm{m}^{3}$

$0.08-0.83$

$0.9-2.0$

10.4-20

0.11

[54]

$[66]$

\section{Boden}

Ackerböden

BRD

dito nach Klärschlammanwendung BRD

dito in Liebefeld

Klärschlamm-Deponien

städtische Gebiete

Schweiz

Gartenböden

Bodenproben

BRD

USA

BRD

Finnland

$\mathrm{mg} / \mathrm{kg}$ TS

0.03

0.44

0.19

$0.8-14.2$

$0.09-3.33$

$0.4-2.5$

$0.05-0.1$ entgegenwirken. In natürlichen Systemen wird die Bioverfügbarkeit von PCBs großen räumlichen und zeitlichen Schwankungen unterworfen sein und ist kaum quantitativ zu erfassen.

Unter komplett reduzierenden, Elektronenacceptoren ermangelnden Bedingun- gen kann es durch anaerobe Bakterien zur reduktiven Dechlorierung von PCBs kommen. Dabei wird die Zahl der Chlorsubstituenten am Biphenyl-Ringgerüst verringert und eine eventuell nachfolgende aerobe Transformation erleichtert. Dies würde allerdings einen 
Transport der Substanzen in eine sauerstoffhaltige Umgebung oder eine Sauerstoffzufuhr in das ursprünglich reduzierende Milieu voraussetzen. Beide Prozesse sind in der Natur nicht auszuschließen, geschehen aber unter Umständen nur sehr selten und sehr langsam.

Die aerobe Transformation hängt $a b$ von der Induktion und Aktivität der Enzyme des Biphenyl-Katabolismus. Voraussetzung ist die Gegenwart von Biphenyl selbst oder von monochloriertem Biphenyl. Häufig gibt es aber an einer mit PCBs verschmutzten Stelle kein Biphenyl. Da es vielen Mikroorganismen als Wachstumssubstrat dient, würde es nach einmaligem Eintrag bald verschwinden und mit ihm auch die darauf gewachsene Population. Um die PCB-Transformation weit fortschreiten zu lassen, müßte Biphenyl während längerer Zeit nachgeliefert werden. Eine solche Maßnahme wäre bei technischen Prozessen in geschlossenen Systemen möglich, würde jedoch zur Unterstützung des bakteriellen PCB-Abbaus an Ort und Stelle der Verunreinigung kaum akzeptiert oder bewilligt werden. Bei durch Biphenyl verwertende Organismen bewirkten aeroben Transformationsvorgängen wird in der Regel der Chlorgehalt nicht vermindert; es entstehen vielmehr hydrophilere chlorierte Metaboliten (polychlorierte Hydroxybiphenyle), deren Eigenschaften - wie Umweltverhalten und Toxizität - noch wenig untersucht und möglicherweise immer noch sehr nachteilig sind.

Es muß angenommen werden, daß mikrobieller PCB-Abbau in der Umwelt nur in jenen glücklichen Fällen stattfindet, in denen alle für die Existenz der dazu fähigen Organismen oder für die gewünschten Stoffwechselaktivitäten notwendigen Bedingungen über lange Zeit erfüllt sind. Die Wahrscheinlichkeit dafür in der Natur muB pessimistisch beurteilt werden.

Durch welche Maßnahmen könnte man den bakteriellen PCB-Abbau unterstïtzen?

Auf molekularer Ebene besteht die Aussicht, mit gentechnischen Methoden gewisse Stoffwechselleistungen zu verbessern. Durch Kombination der Fähigkeit zum Abbau von Biphenyl einerseits und zum Abbau von chlorierten Benzoaten anderseits in einem einzigen Organismus ließen sich viele PCBKongenere im Zuge von Energiegewinnung und Wachstum vollständig mineralisieren. Falls es überdies gelänge, die Regulation der BiphenylabbauEnzyme so zu verändern, daß diese auch in Abwesenheit des Substrats produziert werden, könnten PCB-Umwandlungen auch bei Wachstum der Mikroorganismen auf anderen Kohlenstoffverbindungen erfolgen. Dadurch würde das Ausmaß des Prozesses sicherlich stark erhöht werden. Doch die Absicht, Umweltprobleme mit Hilfe von gentechnologisch veränderten Organismen zu bewältigen, wird von vornherein nicht von allen Seiten begrüßt. Abgesehen davon, daß eine erfolgreiche Entwikklung von "maßgeschneiderten", stabilen Mikroorganismen schwierig und teuer erscheint, wäre ihre spätere Anwendung mit Auflagen - wie Bewilligungspflicht und strenge Überwachung - verbunden und würde kritische Fragen bezüglich der kurz- und langfristigen Störungen von Ökosystemen durch die eingebrachten Organismen hervorrufen. Am ehesten wäre vielleicht der Einsatz solcher Mikroorganismen für technische Reinigungsprozesse in geschlossenen Einrichtungen zu realisieren.

Auf der prozeßtechnischen Ebene gibt es Bestrebungen, anaerobe und aerobe Verfahren - vor allem im Hinblick auf die Behandlung lokaler PCB-Kontaminationen in Böden und Sedimenten zu kombinieren. Eine vorausgehende reduktive Dechlorierung ermöglicht oft erst aerobe Abbau- und Umwandlungsprozesse und vermag diese wesentlich zu beschleunigen.

Nur Forschung kann uns eine Antwort darauf geben, ob die erwähnten Maßnahmen eine Hilfe bieten, die selbstgeschaffene Umweltschädigung zu reparieren.

\section{Literaturverzeichnis}

[1] S. W. Hooper, C. A. Pettigrew, G. S. Sayler: "Ecological fate, effects and prospects for the elimination of environmental polychlorinated biphenyls (PCBs)", Environmental Toxicology and Chemistry 9 (1990) 655-667.

[2] Bundesamt für Umweltschutz: Schutz vor Umweltschäden durch PCB-haltige Kondensatoren und Transformatoren, Schriftenreihe Umweltschutz Nr. 90, Dokumentationsdienst BUWAL, Bern (1988).

[3] K. C. Jones: "Determination of polychlorinated biphenyls in human foodstuffs and tissues: suggestions for a selective congener analytical approach", The Science of the Total Environment 68 (1988) 141-159.

[4] K. Furukawa: "Modification of PCBs by Bacteria and other Microorganisms", in J. S. Waid (Ed.): PCBs and the Environment, CRC Press, Boca Raton FL (1986), p. 89-100.

[5] M. D. Erickson: Analytical chemistry of $P C B s$, Butterworth, Boston MA (1986).

[6] H. Lorenz, G. Neumeier (Ed.) Polychlorierte Biphenyle (PCB)-
Ein gemeinsamer Bericht des Bundesgesundheitsamtes und des Umweltbundesamtes, MMV Medizin Verlag, München (1983).

[7] Deutsche Forschungsgemeinschaft (DFG): Polychlorierte Biphenyle - Bestandsaufnahme von Analytik, Vorkommen, Kinetik und Toxikologie, Mitteilung XIII der Senatskommission zur Prüfung von Rückständen in Lebensmitteln, VCH, Weinheim (1988).

[8] S. Safe, L. Safe, M. Mullin: "Polychlorinated biphenyls: environmental occurence and analysis", in S. Safe, O. Hutzinger (Ed.): Polychlorinated Biphenyls (PCBs): Mammalian and Environmental Toxicology, Springer-Verlag, Berlin (1987), p. 1-13.

[9] L. G. Hansen: "Environmental toxicology of polychlorinated biphenyls", in S. Safe, O. Hutzinger (Ed.): Polychlorinated Biphenyls (PCBs): Mammalian and Environmental Toxicology, Springer-Verlag, Berlin (1987), p. 15-48.

[10] M. D. Mullin, C. M. Pochini, S. McCrindle, M. Romkes, S. H. Safe, L. M. Safe: "Highresolution PCB analysis: synthesis and chromatographic properties of all 209 PCB congeners", Environmental Science and Technology 18 (1984) 468-476.

[11] D. E. Schulz, G. Petrick, J. C. Duinker: "Complete characterization of polychlorinated biphenyl congeners in commercial Aroclor and Clophen mixtures by multidimensional gas chromatographyelectron capture detection", Environmental Science and Technology 23 (1989) 852-859.

[12] R. S. Horvath: "Microbial cometabolism and the degradation of organic compounds in nature", Bacteriological Reviews 36 (1972) 146-155.

[13] M. S. Shields, S. W. Hooper, G. S. Sayler: "Plasmid-mediated mineralization of 4-chlorobiphenyl", Journal of Bacteriology 163 (1985) 882-889.

[14] D. L. Bedard, R. Unterman, L. H. Bopp, M. J. Brennan, M. L. Haberl, C. Johnson: "Rapid assay for screening and characterizing microorganisms for the ability to degrade polychlorinated biphenyls", Applied and Environmental Microbiology 51 (1986) 761-768.

[15] P. Adriaens, H. P. E. Kohler, D. KohlerStaub, D. D. Focht: "Bacterial dehalogenation of chlorobenzoates and coculture biodegradation of 4,4'-dichlorobiphenyl", Applied and Environmental Microbiology 55 (1989) 887-892.

[16] P. Adriaens, D. D. Focht: "Continuous coculture degradation of selected polychlorinated biphenyl congeners by Acinetobacter sp. in an aerobic reactor system", Environmental Science and Technology 24 (1990) 1042-1049.

[17] D. Catelani, C. Sorlini, V. Treccani: "The metabolism of biphenyl by Pseudomonas putida", Experientia 27 (1971) 1173-1174; D. Catelani, A. Colombi, C. Sorlini, V. Treccani: "Metabolism of biphenyl. 2-Hydroxy-6-oxo-6-phenylhexa-2,4dienoate: the meta-cleavage product from 2,3-dihydroxybiphenyl by Pseudomonas putida", Biochemical Journal 134 (1973) 1063-1066;

D. Catelani, A. Colombi: "Metabolism of biphenyl. Structure and physiochemical properties of 2-hydroxy-6-oxo-6-phenylhexa2,4-dienoic acid, the meta-cleavage product from 2,3-dihydroxybiphenyl by

Pseudomonas putida", Biochemical Journal 143 (1974) 431-434: 
D. T. Gibson, R. L. Roberts, M. C. Wells, V. M. Kobal: "Oxidation of biphenyl by a Beijerinckia species", Biochemical and Biophysical Research Communications 50 (1973) 211-219.

18] D. T. Gibson, V. Subramanian: "Microbial degradation of aromatic hydrocarbons", in D. T. Gibson (Ed.): Microbial Degradation of Organic Compounds, Marce Deckker, New York (1984), p. 181-252.

19] A. Ahmed, D. D. Focht: "Degradation of polychlorinated biphenyls by two species of Achromobacter", Canadian Journal of Microbiology 19 (1973) 47-52.

[20] G. S. Sayler, M. Shon, R. R. Colwell: "Growth of an estuarine Pseudomonas sp. on polychlorinated biphenyl", Microbial Ecology 3 (1977) 241-255;

E. Herbst, I. Scheunert, W. Klein, F. Korte: "Fate of PCBs-14C in sewage treatment. Laboratory experiments with activated sludge", Chemosphere 11 (1977) 725-730; A. E. Carey, G. R. Harvey: "Metabolism of polychlorinated biphenyls by marine bacteria", Bulletin of Environmental Contamination and Toxicology 20 (1978) 527-534;

M. P. Shiaris, G. S. Sayler:

"Biotransformation of PCB by natural assemblages of freshwater microorganisms", Environmental Science and Technology 16 (1982) 367-369.

H-L. Kong, G. S. Sayler: "Degradation and total mineralization of monohalogenated biphenyls in natural sediments and mixed bacterial culture", Applied and Environmental Microbiology 46 (1983) 666-672;

P. R. Wallnöfer, G. Engelhardt, S. Safe, O. Hutzinger: "Microbial hydroxylation of 4-chlorobiphenyl and 4,4'-dichlorobiphenyl", Chemosphere 2 (1973) 69-72

P. T. S. Wong, K. L. E. Kaiser: "Bacterial degradation of polychlorinated biphenyls II. Rate studies", Bulletin of Environmental Contamination and Toxicology 13 (1975) 249-256;

E. S. Tucker, V. W. Saeger, O. Hicks:

"Activated sludge primary biodegradation of polychlorinated biphenyls", Bulletin of Environmental Contamination and Toxicology 14 (1975) 705-713; R. Baxter, P. E. Gilbert, R. A. Lidgett, J. H. Mainprize, H. A. Vodden:

"The degradation of polychlorinated biphenyls by microorga-nisms", The Science of the Total Environment 4 (1975) 53-61; R. R. Clark, E. S. K. Chian, R. A. Griffin: "Degradation of polychlorinated biphenyls by mixed microbial cultures", Applied and Environmental Microbiology 37 (1979) 680-685;

D. Liu: "Enhancement of PCBs biodegradation by sodium ligninsulfonate", Water Research 14 (1980) 1467-1475; R. Massé, F. Messier, L. Péloquin, C. Ayotte M. Sylvestre: "Microbial biodegradation of 4-chlorobiphenyl, a model compound of chlorinated biphenyls", Applied and Environmental Microbiology 47 (1984) 947-951

L. H. Bopp: "Degradation of highly chlorinated PCBs by Pseudomonas strain LB400", Journal of Industrial Microbiology 1 (1986) 23-29;

S. Kilpi, K. Himberg, K. Yrjälä,

V. Backström: "The degradation of biphenyl and chlorobiphenyls by mixed bacterial cultures", FEMS Microbiology Ecology 53 (1988) 19-26:
H. J. Neu, K. Ballschmiter: "Abbau von chlorierten Aromaten: Mikrobiologischer Abbau der polychlorierten Biphenyle (PCB) - II. Biphenylole als Metabolite der PCB", Chemosphere 6 (1977) 419-423;

K. Ballschmiter, C. Unglert, H. J. Neu:

"Abbau von chlorierten Aromaten:

Mikrobiologischer Abbau der polychlorierten Biphenyle (PCB) - III: Chlorierte Benzoesäuren als Metabolite der PCB", Chemosphere 6 (1977) 51-56.

[21] D. L. Bedard, R. E. Wagner, M. J. Brennan M. L. Haberl, J. F. Brown: "Extensive degradation of Aroclors and environmentally transformed polychlorinated biphenyls by Alcaligenes eutrophus H850", Applied and Environmental Microbiology 53 (1987) 1094-1102;

D. L. Bedard, M. L. Haberl, R. J. May, M. J. Brennan: "Evidence for novel mechanism of polychlorinated biphenyl metabolism in Alcaligenes eutrophus H850", Applied and Environmental Microbiology 53 (1987) 1103-1112.

[22] H. P. E. Kohler, D. Kohler-Staub, D. D. Focht: "Cometabolism of polychlorinated biphenyls: enhanced transformation of Aroclor 1254 by growing bacterial cells", Applied and Environmental Microbiology 54 (1988) 1940-1945.

[23] K. Furukawa, N. Tomizuka, A. Kamibayashi: "Metabolic breakdown of Kaneclors (polychlorobiphenyls) and their products by Acinetobacter sp.", Applied and Environmental Microbiology 46 (1983) 140-145.

[24] W. Brunner, F. H. Sutherland, D. D. Focht: "Enhanced biodegradation of polychlorinated biphenyls in soil by analog enrichment and bacterial inoculation", Journal of Environmental Quality 14 (1985) 324-328.

[25] K. Furukawa, K. Tonomura, A. Kamibayashi: "Effect of chlorine substitution on the biodegradability of polychlorinated biphenyls", Applied and Environmental Microbiology 35 (1978) 223-227.

[26] K. Furukawa, N. Tomizuka, K. Tonomura: "Alcaligenes and Acinetobacter strains capable of degrading polychlorinated biphenyls", Agricultural and Biological Chemistry 42 (1978) 543-548,

K. Furukawa, K. Tonomura, A. Kamibayashi: "Metabolism of 2,4,4', Trichlorobiphenyl by Acinetobacter sp. P6", Agricultural and Biological Chemistry 43 (1979) 1577-1583.

[27] K. Furukawa, N. Tomizuka, A. Kamibayashi: "Effect of chlorine substitution on the bacterial metabolism of various polychlorinated biphenyls", Applied and Environmental Microbiology 38 (1979) 301-310.

[28] D. D. Focht, W. Brunner: "Kinetics of biphenyl and polychlorinated biphenyl metabolism in soil", Applied and Environmental Microbiology 50 (1985) 1058-1063.

[29] H. P. E. Kohler, D. Kohler-Staub D. D. Focht: "Degradation of 2hydroxybiphenyl and 2,2'-dihydroxybipheny by Pseudomonas sp. strain HBP1", Applied and Environmental Microbiology 54 (1988) 2683-2688

[30] W. Reineke: "Microbial degradation of halogenated aromatic compounds", in D. T. Gibson (Ed.): Microbial Degradation of Organic Compounds, Marcel Dekker.
New York (1984), p. 319-360.

[31] D. Kohler-Staub, H. P. E. Kohler: "Microbia: degradation of $\beta$-chlorinated four-carbon aliphatic acids", Journal of Bacteriology 171 (1989) 1428-1434.

[32] K. Furukawa, T. Miyazaki: "Cloning of a gene cluster encoding biphenyl and chlorobiphenyl degradation in Pseudomonas pseudoalcaligenes", Journal of Bacteriology 166 (1986) 392-398.

[33] K. Furukawa, N. Hayase, K. Taira: "Bipheny1/polychlorinated biphenyl catabolic a... (bph operon): organization, function, and molecular relationship in various pseudomonads", in S. Silver, A. M. Chakrabarty, B. Iglewski, S. Kaplan (Ed.): Pseudomonas Biotransformations, Pathogenesis, and Evolving Biotechnology, American Society for Microbiology, Washington DC (1990), p. 111-120

[34] F. J. Mondello: "Cloning and expression in Escherichia coli of Pseudomonas strain LB400 genes encoding polychlorinated biphenyl degradation", Journal of Bacteriology 17I (1989) 1725-1732.

[35] D. Ahmad, S. Massé: "Cloning and expression of genes involved in 4-chlorobiphenyl transformation by Pseudomonas testosteroni: homology to polychlorobiphenyl-degrading genes in othel bacteria", Gene 86 (1990) 53-61.

[36] A. Khan, S. Walia: "Cloning of bacterial genes specifying degradation of 4-chlorobiphenyl from Pseudomonas putida OU83", Applied and Environmental Microbiology 55 (1989) 798-805.

[37] S. Walia, A. Khan, N. Rosenthal: "Construction and applications of DNA probes for detection of polychlorinated biphenyl-degrading genotypes in toxic organic-contaminated soil environments", Applied and Environmental Microbiology 56 (1990) 254-259.

[38] J. F. Brown, R. E. Wagner, D. L. Bedard, M. J. Brennan: "PCB transformations in upper Hudson sediments", Northeastern Environmental Sciences 3 (1984) 167-179.

[39] J. F. Brown, D. L. Bedard, M. J. Brennan, J. C. Carnahan, H. Feng, R. E. Wagner: "Polychlorinated biphenyl dechlorination in aquatic sediments", Science 236 (1987) 709-712.

[40] B. Bush, L. A. Shane, M. Wahlen, M. P. Brown: "Sedimentation of 74 PCB congeners in the upper Hudson River", Chemosphere 16 (1987) 733-744;

M. P. Brown, B. Bush, G. Y. Rhee, L. Shane "PCB dechlorination in Hudson River sediment", Science 240 (1988) 1674-1675.

[41] J. F. Quensen, J. M. Tiedje, S. A. Boyd: "Reductive dechlorination of polychlorinated biphenyls by anaerobic microorganisms from sediments", Science 242 (1988) 752-754.

[42] J. F. Quensen, S. A. Boyd, J. M. Tiedje: "Dechlorination of four commercial polychlorinated biphenyl mixtures (Aroclors) by anaerobic microorganisms from sediments", Applied and Environmental Microbiology 56 (1990) 2360-2369.

[43] S. O. Farwell, F. A. Beland, R. D. Geer: "Interrupted-sweep voltammetry for the identification of polychlorinated biphenyls and naphtalenes", Analytical Chemistry 47 (1975) 895-903 J. F. Rusling, C. L. Miaw: "Kinetic estimation of standard reduction potentials s polyhalogenated biphenyls", Environmental 


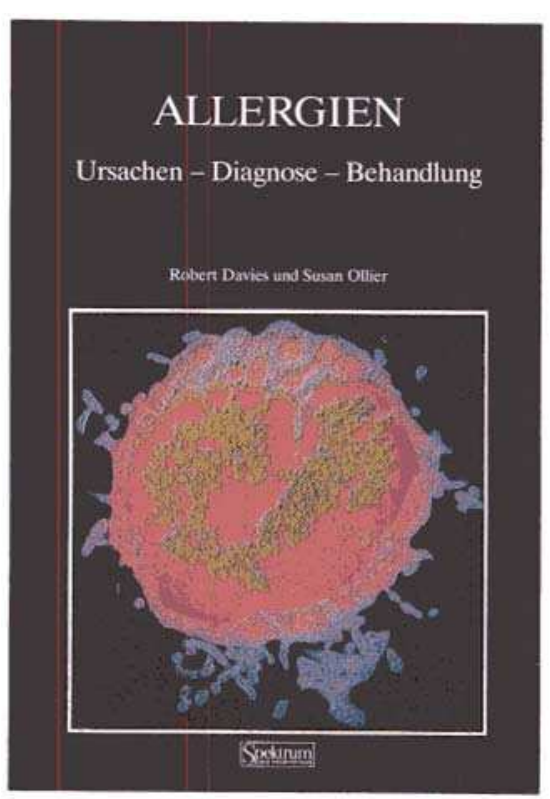

\section{Immunsystem auf Abwegen}

Immer mehr Menschen leiden unter Allergien. Obwohl von dieser Überreaktion des Immunsystems bereits jeder 10 . Erwachsene und jedes 20 . Kind betroffen sind, spielt die Allergologie im Medizinstudium noch eine untergeordnete Rolle. Unter den medizinischen Laien ist zwar das Interesse an diesem Thema groß, das Wissen über Allergien jedoch beschränkt. Diesen Personenkreis möchten Davies und Ollier mit ihrem Buch ansprechen. Sie beschreiben die Hauptursachen und die wichtigsten Symptome von so weit verbreiteten Erkrankungen wie Heuschnupfen, Asthma, Bronchitis und Ekzeme. Dabei legen sie besonderen Wert auf das Verständnis der Arbeitsweise des Immunsystems und dessen Reaktionen auf den Kontakt mit allergieauslösenden Stoffen. Die Autoren erörtern die verschiedenen medizinischen Behandlungsmöglichkeiten, geben aber auch praktische Ratschläge, wie Allergien durch gezielte Verhaltensweisen und eine bewußte Lebensweise gemildert werden können.

200 Seiten, ISBN 3-89330-714-1

Preis DM 38, - / sfr 36, - / öS 296,-

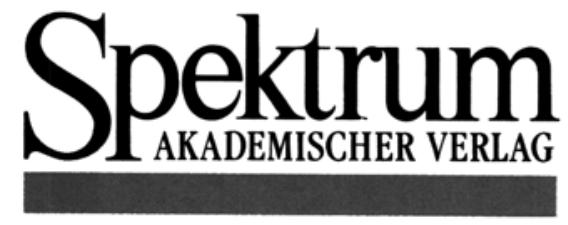

Mönchhofstraße 15 - D-6900 Heidelberg
Science and Technology 23 (1989) 476-479.

[44] L. Nies, T. M. Vogel: "Effects of organic substrates on dechlorination of Aroclor 1242 in anaerobic sediments", Applied and Environmental Microbiology 56 (1990) 2612-2617.

[45] A. C. Alder, M. M. Häggblom, L. Young: "Dechlorination of PCBs in sediments under sulfate reducing and methanogenic conditions", Water Pollution Research Reports 25 (1991) 115-122.

[46] H. M. van Dort, D. L. Bedard: "Reductive ortho and meta dechlorination of polychlorinated biphenyl congeners by anaerobic microorganisms", Applied and Environmental Microbiology 57 (1991) 1576-1578.

[47] J. F. Brown, R. E. Wagner: "PCB movement, dechlorination, and tetoxification in the Acushnet estuary", Environmental Toxicology and Chemistry 9 (1990) 1215-1233.

[48] L. DeAlencastro, J. Tarradellas: "Etude de la concentration en PCB des eaux usées dans les stations d'épuration", Gas-WasserAbwasser 63 (1983) 113-130.

[49] W. Giger: "Organische Verunreinigungen im Klärschlamm: Herkunft und Verhalten in der Umwelt", Mitteilungen der EAWAG 28 (1989) 8-11.

[50] F. Selenka: "Ergebnisse über die Verunreinigung von Oberflächengewässern mit polychlorierten Biphenylen", Schriftenreihe des Vereins für Wasser-, Boden- und Lufthygiene 37 (1972) 113-120.

[51] J. C. Colombo, M. F. Khalil, M. Arnac, A. C. Horth, J. A. Catoggio: "Distribution of chlorinated pesticides and individual polychlorinated biphenyls in biotic and abiotic compartments of the Rio de La Plata, Argentina", Environmental Science and Technology 24 (1990) 498-505.

[52] M. Brinkman, K. Fogelman, J. Heflein, T. Lindh, M. Pastel, W. C. Trench, D. A. Aikens: "Distribution of polychlorinated biphenyls in the Fort Edward, New York, water system",

Environmental Managemen 4 (1980) 511-520.

[53] M. P. Brown, M. B. Werner, R. J. Sloan, K. W. Simpson: "Polychlorinated biphenys in the Hudson river",

Environmental Science and Technology 19 (1985) 656-661.

[54] J. E. Baker, S. J. Eisenreich: "Concentrations and fluxes of polycyclic aromatic hydrocarbons and polychlorinated biphenyls across the air-water interface of Lake Superior", Environmental Science and Technology 24 (1990) 342-352.

[55] P. Claus: "PCB-Gehalte in Oberflächengewässern", in H. Lorenz, G. Neumeier (Ed.): Polychlorierte Biphenyle -

Ein gemeinsamer Bericht des Bundesgesundheitsamtes und des Umweltbundesamtes, MMV Medizin Verlag, München (1983), p. 92-98.

[56] R. H. Bopp, H. J. Simpson, C. R. Olsen, N. Kostyk: "Polychlorinated biphenyls in sediments of the tidal Hudson River", Environmental Science and Technology 15 (1981) 210-216.

[57] B. J. Brownawell, W. Farrington: "Biogeochemistry of PCBs in interstitial waters of a coastal marine sediment", Geochimica et Cosmochimica Acta 50 (1986) 157-169.

[58] A. L. Alford-Stevens, J. W. Eichelberger,
W. L. Budde: "Multilaboratory study of automated determinations of polychlorinated biphenyls and chlorinated pesticides in water, soil, and sediment by gas chromatography/mass spectrometry", Environmental Science and Technology 22 (1988) 304-312.

[59] S. J. Eisenreich, B. B. Looney, J. D. Thornton: "Airborne organic contaminants in the Great Lakes ecosystem", Environmental Science and Technology 15 (1981) 30-38.

[60] R. A. Rapaport, S. J. Eisenreich: "Historical atmospheric inputs of high molecular weight chlorinated hydrocarbons to Eastern North America", Environmental Science and Technology 22 (1988) 931-941.

[61] L. DeAlencastro, J. Tarradellas: - "Origine et bilan des polychlorobiphenyls (PCB) dans les eaux usées Suisse", Gas-Wasser-Abwasser 68 (1988) 120-130.

[62] J. C. Duinker: "On the distribution of atmospheric polychlorinated biphenyl congeners between vapor phase, aerosols, and rain", Environmental Science and Technology 23 (1989) 57-62.

[63] P. C. Capel, C. Leuenberger, W. Giger: "Hydrophobic organic chemicals in urban fog", Atmospheric Environment 25A (1991) 1335-1346.

[64] K. Ballschmiter, C. Rappe, H. R. Buser: "Chemical properties, analytical methods and environmental levels of PCBs, PCTs, PCNs and PBBs", in R. D. Kimbrough, A. A. Jensen (Ed.): Halogenated Biphenyls, Terphenyls, Naphtalenes, Dibenzodioxins and Related Compounds, Elsevier. Amsterdam (1989), p. 47-69.

[65] M. H. Hermanson, R. A. Hites: "Long-term measurements of atmospheric polychlorinated biphenyls in the vicinity of superfund dumps",

Environmental Science and Technology 23 (1989) 1253-1258.

[66] S. Tanabe, H. Hidaka, R. Tatzukawa "PCBs and chlorinated hydrocarbon pesticides in Antarctic atmosphere and hydrosphere",

Chemosphere 12 (1983) 277-288.

[67] A. Marcomini, P. D. Capel, W. Giger, H. Häni: "Residue of detergent-derived organic pollutants and polychlorinated biphenyls in sludge-amended soil", Naturwissenschaften 75 (1988) 460-462.

[68] A. Marcomini, P. D. Capel, T. Lichtensteiger, P. H. Brunner, W. Giger: "Behaviour of aromatic surfactants and PCBs in sludgetreated soil and landfills", Journal of Environmental Quality 18 (1989) 523-528.

[69] A. E. Carey, J. A. Gowen: "PCBs in agricultural and urban soil", in National Conference on Polychlorinated Biphenyls, Chicago 1975, EPA, Washington DC (1976), p. 195-198.

[70] J. Scheunert, W. Klein: Polychlorinated Biphenyls in the Environments - Report of Experimental Investigations, Institut für Ökologische Chemie der Gesellschaft für Strahlen- und Umweltforschung, München (1979).

[71] J. Rautapää, A. Myllymäki, H. Siltanen, V. Mattinen: "Endrin, DDT and PCBs in finnish soils", Journal of the Scientific Agricultural Society of Finland 48 (1976) 181-186. mitgeteilt von W. Giger) 